\title{
Developments in Global Natural Gas Consumption
}

China is a country rich in coal but lacking in oil. For many years, coal has held the leading position in the country's energy mix, while petroleum and natural gas consumption has been low. Recently, with economic growth and increasing energy consumption, the increasing pressure on the environment brought about by the extensive use of coal has led to unprecedented attention being paid to the development of clean energy by the state. On the supply side, the development of shale natural gas, coalbed methane and other unconventional gas sources has also been accompanied by greater development of conventional gas sources. Natural gas import volumes are also expected to grow. If China's natural gas supply capabilities continue to grow at the current rapid rates, then in the future supply will no longer be the primary obstacle to the development of natural gas. Given these circumstances, research into applications for natural gas and its development potential, allowing targeted measures to support the growth of natural gas consumption, is of major significance in the promotion of the adoption of natural gas.

\footnotetext{
* This chapter was overseen by Zhaoyuan Xu from the Development Research Center of the State Council and Martin Haigh from Shell International, with contributions from Baosheng Zhang and Shouhai Chen from the China University of Petroleum, Lianzeng Zhao from the China Petroleum Planning Research Institute, Linji Qiao from ENN and Juan Han from Shell China. Other members of the research group participated in discussions and revisions.
}

\subsection{Major Factors Affecting Natural Gas Consumption Growth in Other Countries}

In recent years, natural gas consumption grown rapidly in many countries, so that it accounts for an increasing proportion of energy used. China can learn crucial lessons by analysing natural gas consumption growth in these countries.

\subsubsection{Proportion of Energy Consumption of Natural Gas in Various Countries}

The horizontal axis in Fig. 2.1 indicates the proportion of energy consumption represented by natural gas (0-100\%, divided equally into 10 groups) while the vertical axis indicates the proportion of natural gas consumption of each country compared to global natural gas consumption. It is clear that, out of 103 countries (or regions), there are 29 countries whose natural gas proportion is between $0-10 \%$ of total energy consumption and these 29 countries account for $8.34 \%$ of global natural gas consumption. There are 14 countries whose natural gas consumption is between $20-30 \%$ of total energy consumption and these 14 countries account for around $32.7 \%$ of global natural gas consumption. There are another 19 countries whose natural gas consumption is between $30-40 \%$ of total energy consumption, accounting for around $19.64 \%$ of 


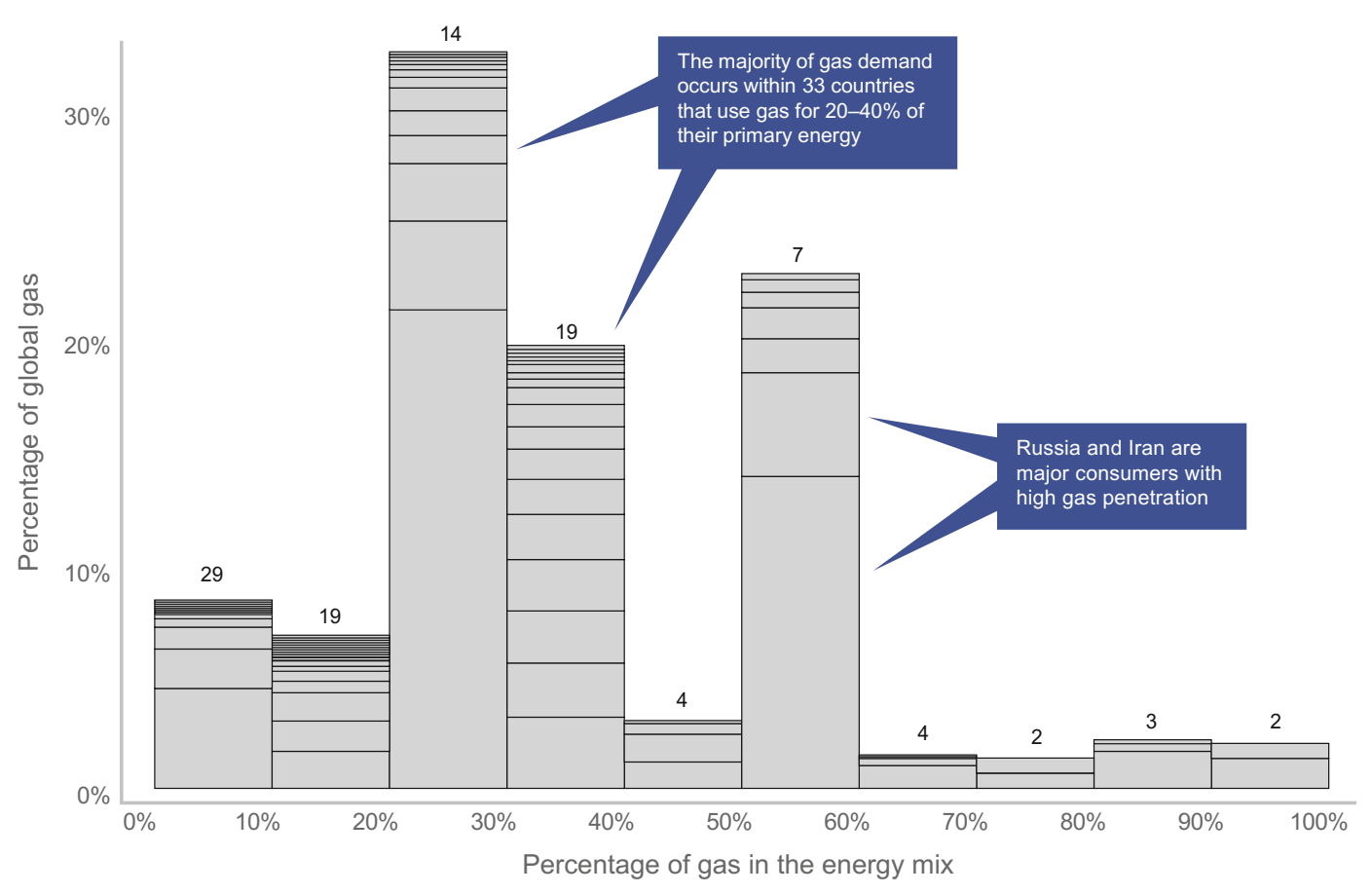

Fig. 2.1 Proportion of energy consumption of each country accounted for by natural gas and proportion of global natural gas consumption of each country. Source Formulated by Vivid Economics based on IEA and EIA data

global natural gas consumption. There are few countries where natural gas usage accounts for a proportion greater than $40 \%$, and these countries often possess large quantities of natural gas reserves. However, with the exception of Iran and Russia, these countries are not major natural gas consumers in terms of quantity. The majority of global natural gas demand comes from countries where natural gas usage accounts for between $20-30 \%$ and $30-40 \%$ of total energy structure.

In order to analyse the prospective growth of China's natural gas consumption, we chose seven countries to act as "benchmark countries" for China, and carried out detailed analysis of the growth in consumption of natural gas in these seven countries. Each of these seven countries is a major consumer of natural gas, and the proportion of energy consumption accounted for by natural gas has increased relatively quickly in each case. Of these, four countries are developed countries: the United States, Japan, Germany and the United Kingdom. There are also three emerging countries: Malaysia, Turkey and Egypt. There are other major natural gas-consuming nations where the proportion of energy usage accounted for by natural gas is quite high, but these have large natural gas reserves, excluding them from the comparison due to China's relatively small reserves. In addition, there are countries where growth in natural gas consumption has been slow over a number of decades, which are therefore not suitable for adoption as "benchmarks" for the analysis of China's future natural gas demand (Fig. 2.2).

Since 1982, the proportion of natural gas consumption of these benchmark countries exhibited major increases, especially in the three emerging countries of Turkey, Malaysia and Egypt, where natural gas proportions have risen from very low levels to extremely high levels over the past 30 years. During this same period, the proportion of energy sources that natural gas 


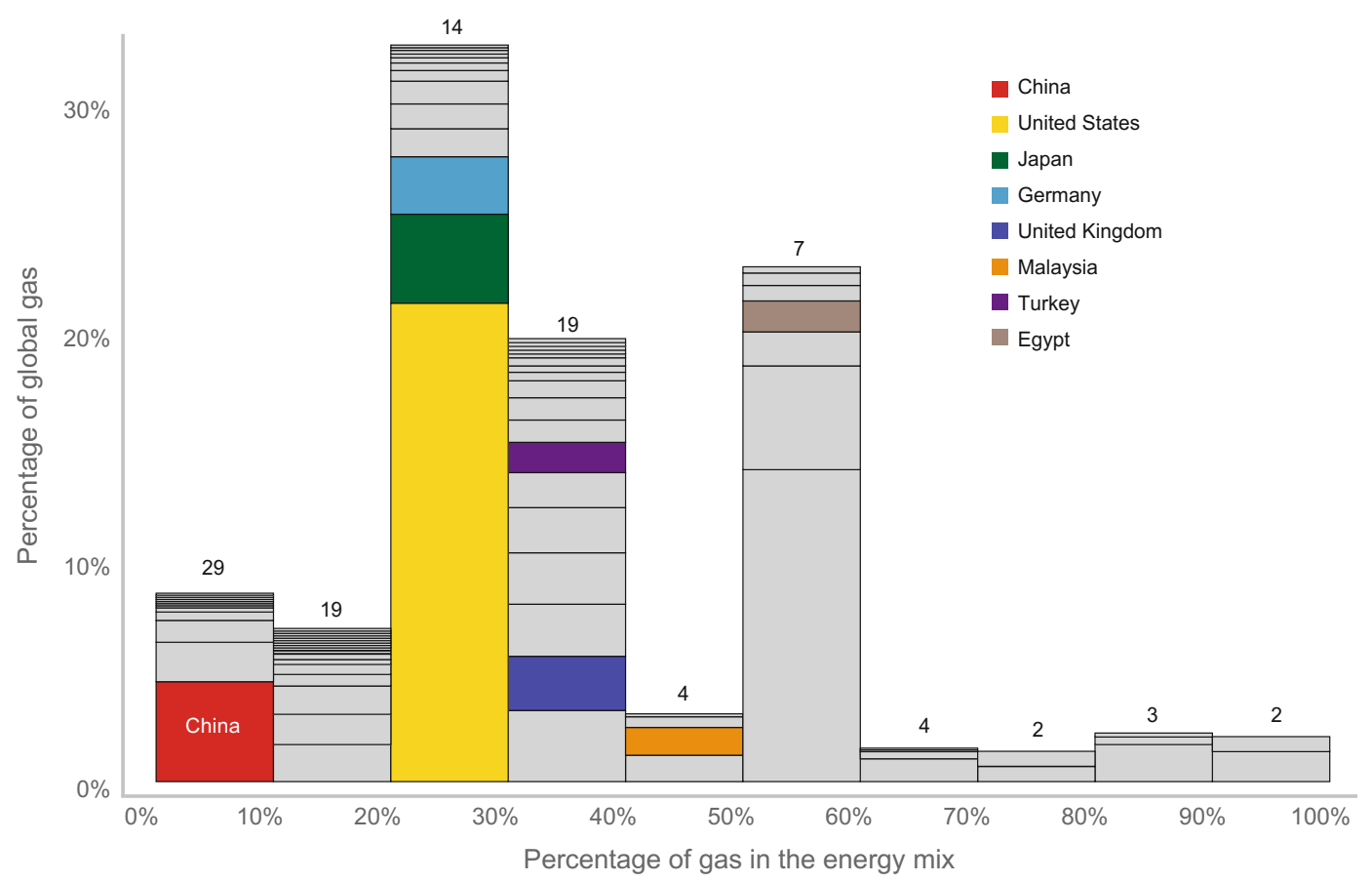

Fig. 2.2 Natural gas consumption in seven benchmark countries. Source Formulated by Vivid Economics based on IEA and EIA data

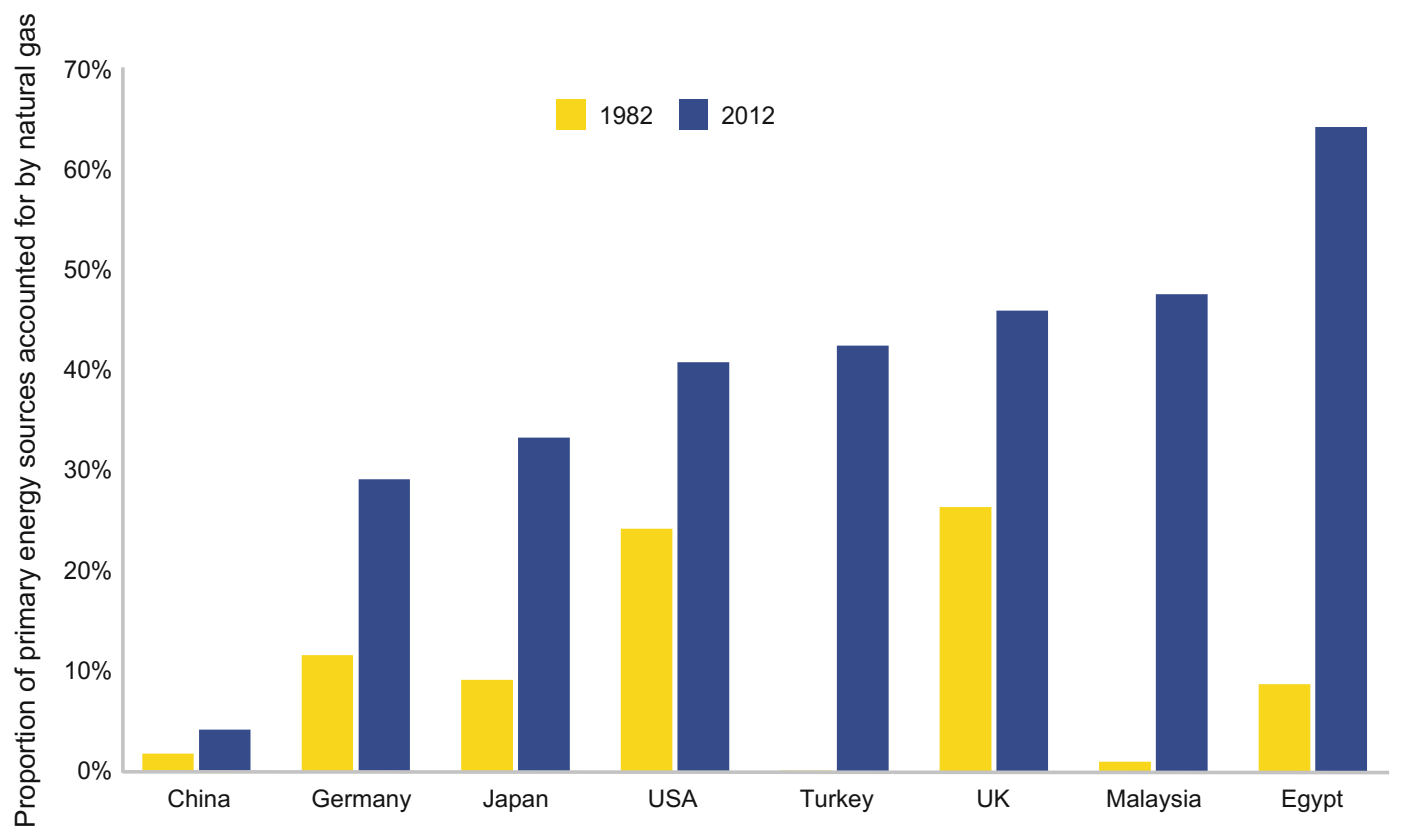

Fig. 2.3 Changes between 1982 and 2012 in the proportion of natural gas consumption of seven benchmark countries. Source Formulated by Vivid Economics based on IEA data 
accounted for in China rose from $2 \%$ in 1982 to $4 \%$ in 2012 (Fig. 2.3). This indicates that an increase in the proportion of energy sources accounted for by natural gas could occur.

\subsubsection{Breakdown of Natural Gas Consumption Growth in Seven Benchmark Countries}

To carry out analysis of the natural gas consumption growth in these seven benchmark countries, we used index breakdown analysis methods, carrying out quantified analysis of the most important factors driving natural gas demand, allowing the degree to which various factors contributed to the growth in natural gas demand to be calculated. The main factors include economic activity, energy density and fuel conversion.

\section{Method of analysis}

In different economic sectors, natural gas demand changes are related to changes in economic activity, energy density and proportion of natural gas usage. Each economic sector's natural gas demand can be expressed as a function that includes a series of drivers (namely, economic activity, energy density and proportion of energy usage represented by natural gas), as shown in the equation below:

$$
\begin{aligned}
& \underset{\text { demand }}{\text { Gas }}= \sum_{i}^{\text {sectors }} \begin{array}{c}
\text { economic } \\
\text { activity }
\end{array}{ }_{i} \times \begin{array}{c}
\text { energy } \\
\text { intensity }
\end{array} \\
& \times \quad \text { share of energy } \\
& \text { from gas }
\end{aligned}
$$

In the equation above, the total natural gas demand $\mathrm{G}$ is broken down into the sums of the natural gas demand of various sectors $\mathrm{G}_{i}(i=1$, $\ldots, \mathrm{n})$. The natural gas demand of each sector is then broken down into three parts, namely each sector's economic total $\mathrm{GVA}_{i}$, energy intensity $\frac{\mathrm{E}_{i}}{\mathrm{GVA}_{i}}$ and natural gas share of total energy consumption in the sector $\frac{\mathrm{G}_{i}}{\mathrm{E}_{i}}$. Based on natural gas demand functions, indexes can be set for each driver, and these indexes can be broken down again to quantify the change that occurs to natural gas demand due to changes in each driver over a period of time. This kind of index breakdown approach is called a logarithmic mean Divisia index (LMDI). LMDI is a common analytical method found in energy literature. Based on the relative changes of each variable driving factor, it breaks changes in overall natural gas demand into the effects of three factors. This allows the analysis of natural gas growth prospects from the perspective of each factor's development trends. Due to the limitations in the data, the influence of fuel price changes has not been eliminated from the LMDI used in this analysis.

$G=\sum_{i=1}^{n} G V A_{i} \times \frac{E_{i}}{G V A_{i}} \times \frac{G_{i}}{E_{i}} \rightarrow \sum_{i=1}^{n} G V A_{i} \times \frac{E_{i}}{G V A_{i}} \times \frac{G_{i}}{E_{i}} \rightarrow \sum_{i=1}^{n} G_{i}$

Theoretically speaking, these three driving factors will affect natural gas demand in different ways:

- Economic activity: As economic activity grows, the energy input required by such economic activity grows as well, so if all other factors remain equal, natural gas demand will also exhibit a corresponding increase.

- Energy intensity: When the level of economic activity remains unchanged, then as energy consumption intensity drops, the amount of energy required to create the same amount of economic activity is reduced, and thus energy demand will drop. If all other factors remain equal, total natural gas demand will exhibit a corresponding drop.

- Conversion to natural gas: If a given economic sector converts from coal or other fuels to natural gas, then natural gas demand will increase.

\section{Breakdown of factors affecting interna- tional natural gas demand}

This section presents a breakdown of natural gas demand changes in the seven benchmark 


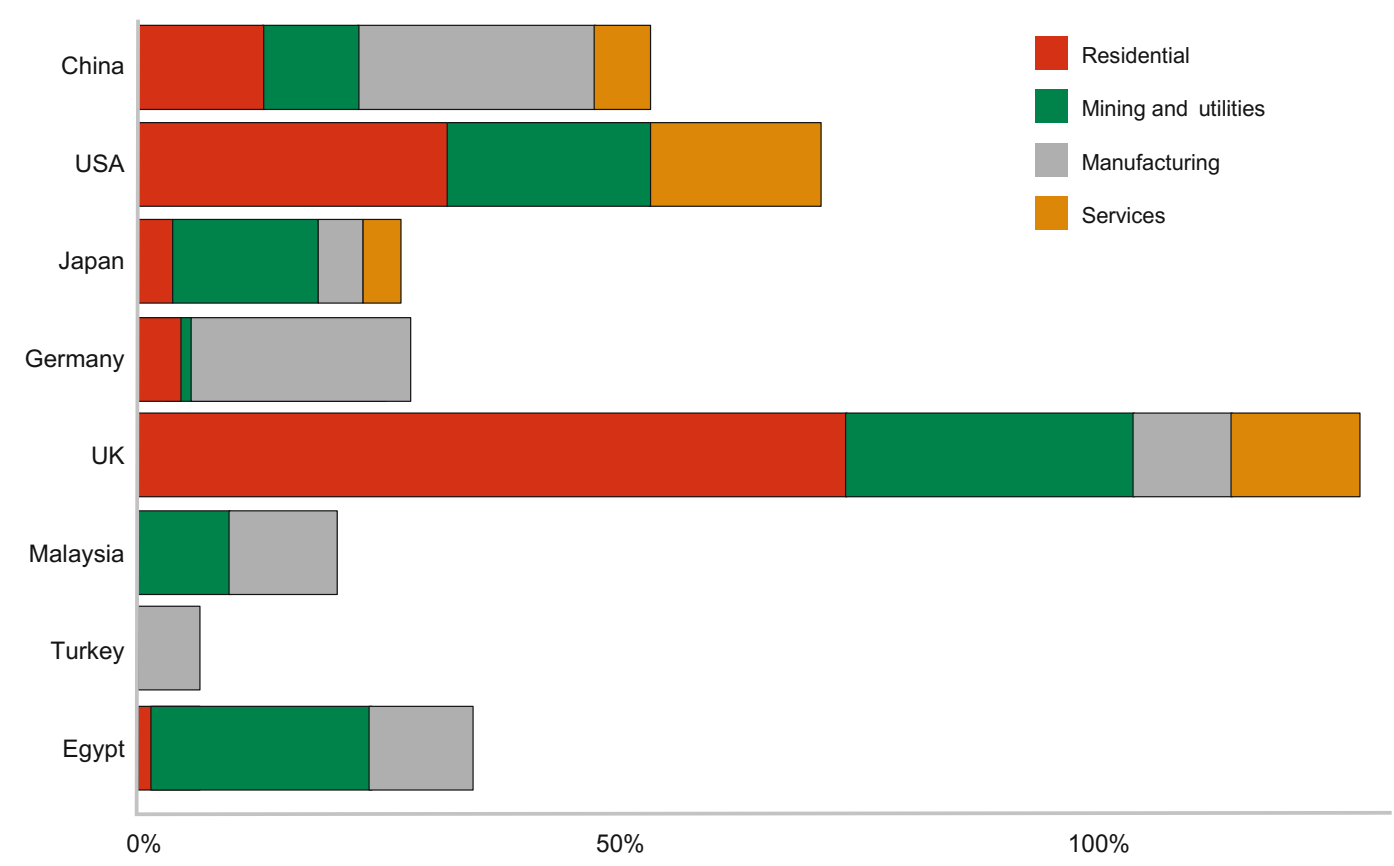

Fig. 2.4 Contribution of increased economic activity in increasing demand for natural gas. Source Formulated by Vivid Economics based on UN and IEA data

countries between 1982 and 2012, and for China between 2005 and 2012, based on LMDI. ${ }^{1}$

\section{(I) Influence of economic growth on natural gas consumption}

As economic activity increases, each sector's natural gas demand will increase. Figure 2.4 shows the proportion that the increase in natural gas demand as a result of economic growth encountered in the seven benchmark countries between 1982 and 2012 represents in terms of actual growth in demand (treating actual total natural gas growth in consumption as $100 \%$ ). It is clear that in these seven benchmark countries the economic activities in all economic sectors grew, and each sector's natural gas demand also rose. However, the most notable increases were in the residential and public utility sectors. The

\footnotetext{
${ }^{1}$ The period over which analysis is possible for China is relatively short, mainly due to the difficulties encountered in obtaining the pre-2005 data required to carry out this analysis.
}

possible cause of this may have been that as incomes increased, household heating expenditure rose, and this was accompanied by increased usage of natural gas in power systems to satisfy the increased power demands. In addition, there was a growth in natural gas demand for manufacturing in each country. This is an indication that as economic activity increases, more natural gas is needed to satisfy the ever-growing demand for energy.

\section{(II) Influence of energy intensity on natural gas consumption}

Reduced economic sector energy intensity implies that the amount of natural gas required to generate the same output has dropped. Natural gas demand in China, the United States, Germany and the United Kingdom has seen a net reduction, which is primarily due to a decline in residential and manufacturing energy intensity (Fig. 2.5). There are also some countries, such as the United States, Japan and Egypt, where the mining industry and public utility sector energy intensity 


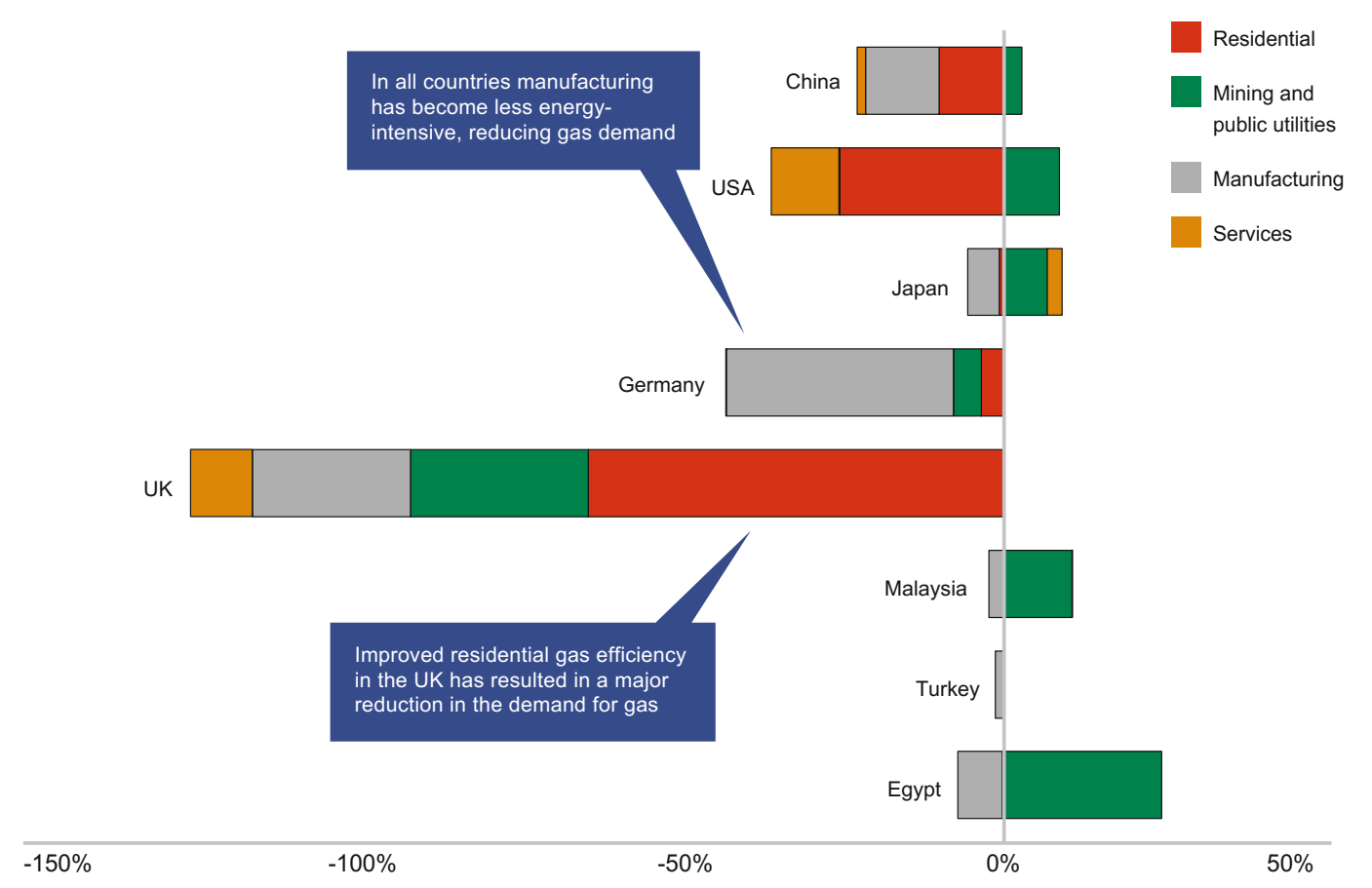

Fig. 2.5 Influence of energy intensity changes on natural gas demand. Source Formulated by Vivid Economics based on UN and IEA data

have seen increases. However, since it is not possible to break down mining industry, public utility and heating plant data, the underlying causes of these increases is difficult to analyse. In addition, over the same period of time, the non-gas-consuming sectors of the economy of any particular country (such as economic activity that requires electrical power) may also exhibit reduced energy intensity, resulting in an overall improvement in total energy intensity of these countries, such as that encountered in Japan. The results of this breakdown indicate that China, the United States, Germany and the United Kingdom all show reduced demand for natural gas as a result of reduced energy intensity.

\section{(III) Influence of fuel conversion on natural gas consumption}

Among the seven benchmark countries, all economic sectors chose to reduce usage of other fuels and to increase the proportion of natural gas. In other words, they achieved fuel switching. This is a major factor behind the increase in natural gas demand (Fig. 2.6). The effect was particularly marked in the mining and public utility sectors, and their fuel conversion and the corresponding natural gas demand increase accounted for a large proportion of growth in consumption. In addition, China, Germany, the United Kingdom and Turkey, among other countries, also saw residential usage fuel conversion, which resulted in an increase in demand for natural gas. In the United States and Malaysia, manufacturing exhibited a relatively large-scale transition towards natural gas. In Japan, Germany and the United Kingdom, the service industry also showed similar trends.

\subsubsection{The Importance of Fuel Switching in Natural Gas Demand Growth}

Figure 2.7 is a summary of each country's natural gas consumption growth factors for 


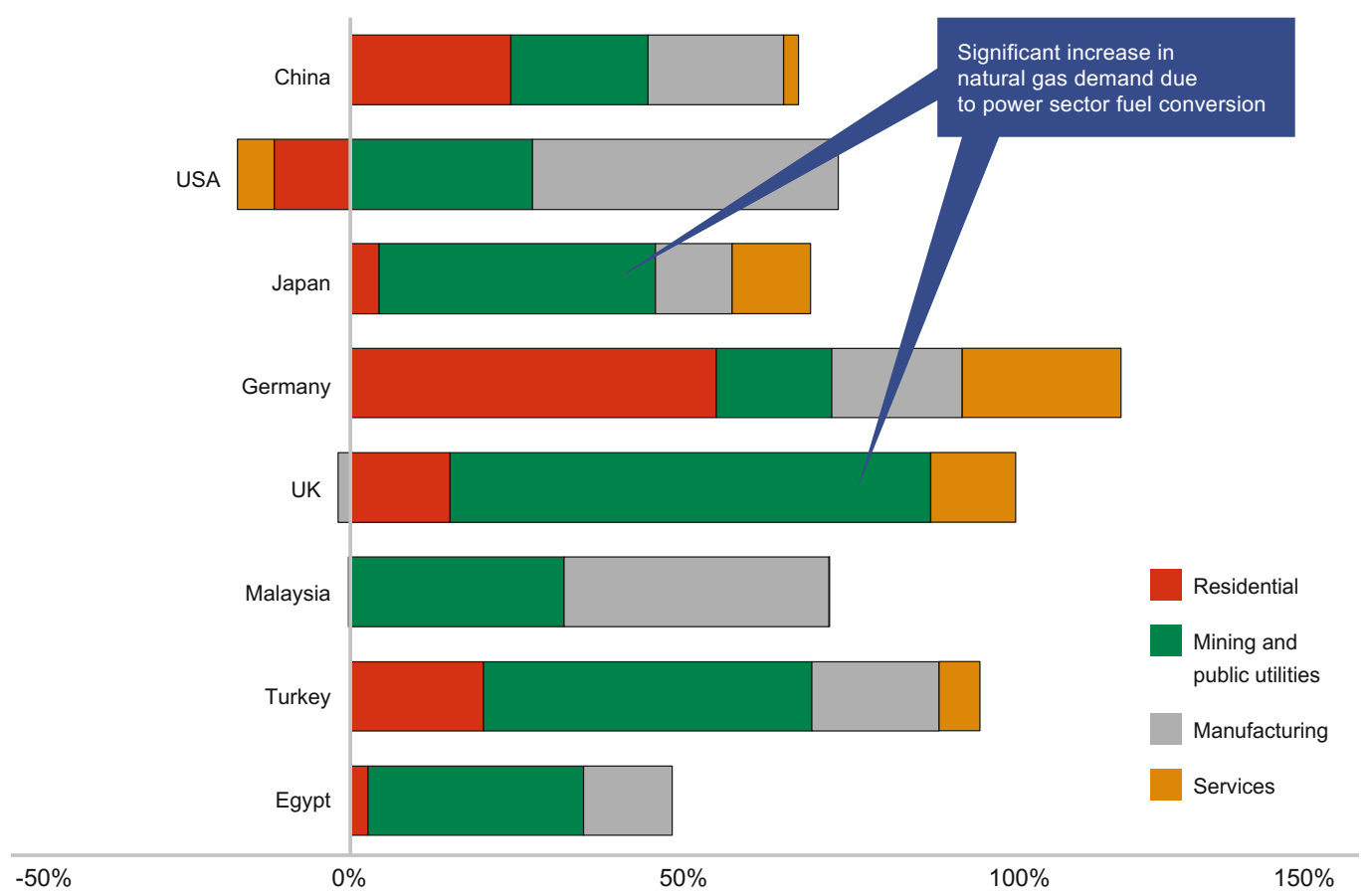

Fig. 2.6 Influence of fuel switching on natural gas demand. Source Formulated by Vivid Economics based on UN and IEA data

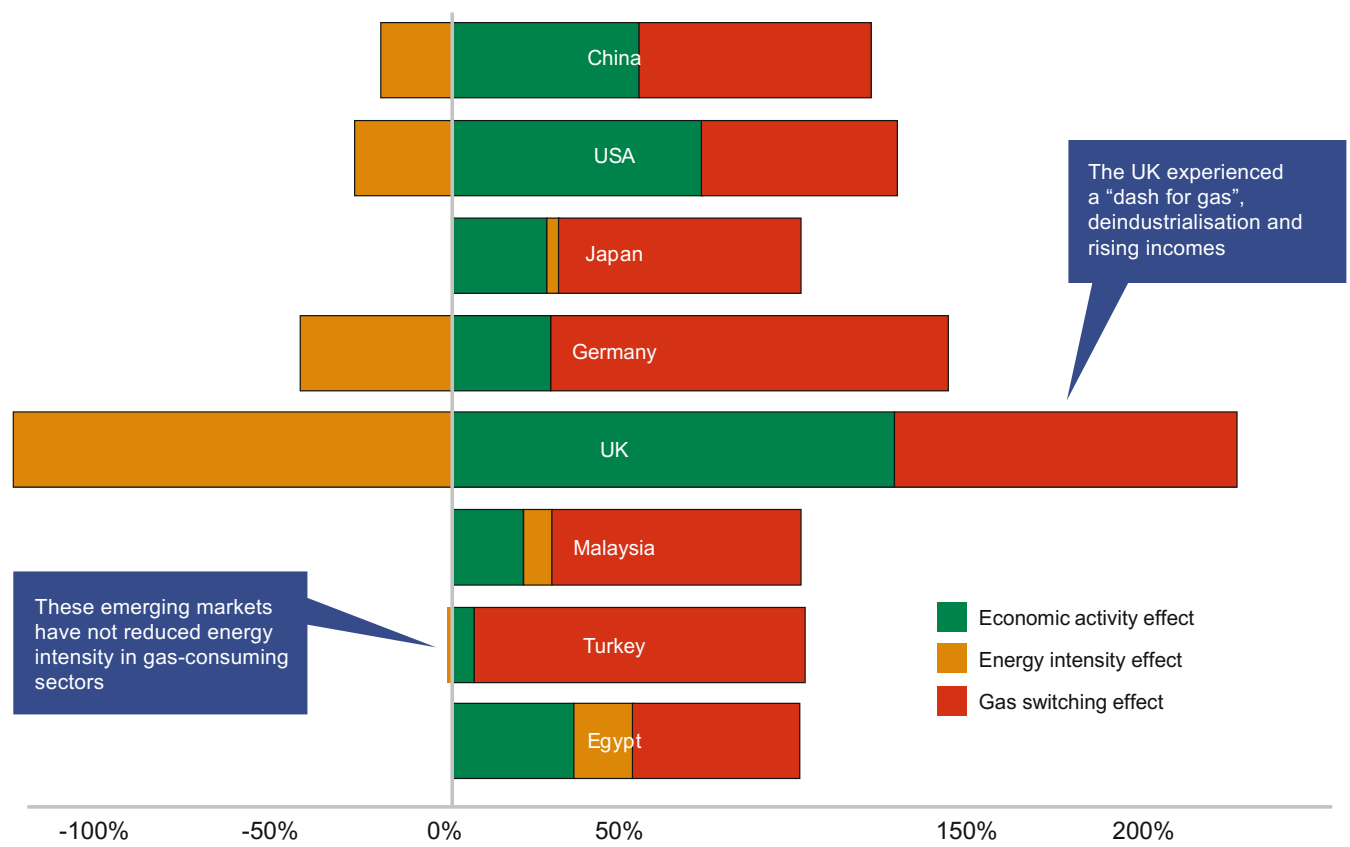

Fig. 2.7 Factor breakdown of benchmark country natural gas demand: overall results. Source Formulated by Vivid Economics based on UN and IEA data 
1982-2012 (China 2005-2012) (each country's natural gas demand total change is set at 100\%), giving an indication of the relative importance of each factor. From Fig. 2.7 we can see that, apart from the United States, in all other countries the influence of switching from other fuels to natural gas on natural gas demand was greater than that of economic activity. This shows that the main driver behind natural gas demand increases is the choice to adopt natural gas as a replacement for other fuels.

Analysis of this breakdown found that the nature of natural gas demand in the United Kingdom was different from other countries. In fact, all three drivers have a major influence in the United Kingdom. Between 1982 and 2012 the United Kingdom was primarily influenced by three major development trends:

- the "dash for gas"-many people converted from coal to natural gas, which played a major role in the overall fuel conversion figures;

- growth in GDP, which made the effects of economic activity more apparent;

- de-industrialisation and schemes to improve household energy efficiency, which resulted in a major increase in energy efficiency and had an opposite effect on natural gas demand.

Even though energy intensity factors can cause demand for natural gas to decline, the other two factors caused natural gas demand to increase. Each of these factors had a very significant result, equivalent to the total change in natural gas demand during the same period. The experience of the United Kingdom shows that, given the circumstances soon to be faced by China, for instance rapid development of domestic natural gas resources, high rates of economic growth and the economy becoming more service industry-oriented, factors that drive up natural gas demand will continue to be very significant.

Generally speaking, the seven benchmark countries analysed each experienced a large increase in natural gas demand. A detailed analysis of the results based on economic sector shows that each of the three factors has the effect of influencing demand for natural gas as follows:

- Increased economic activity will cause natural gas demand in all economic sectors to increase, especially the power-hungry sectors of housing, mining and public utilities.

- Reduced energy intensity in residential housing and manufacturing will cause reduced natural gas demand.

- Fuel conversion is an important driver, in which the primary driver is the conversion of power plants and heating facilities to natural gas, while residential housing and manufacturing sector fuel conversion was also a major factor in most countries.

\subsection{Primary Factors Motivating Switching from Other Fuels to Natural Gas}

Based on international experience, natural gas is generally uncompetitive on pricing alone, compared to other fuels. It follows that there are other factors that contribute to the decision to switch from other fuels to natural gas and it is therefore necessary to explore these less-obvious factors more deeply.

This research employs two methods to explore the motivating factors behind fuel switching. The first consists of cross-sectional regression analysis conducted on the 2012 data for OECD countries, focusing on factors including: the share of the economy accounted for by the service industry; whether or not there are natural gas reserves; total natural gas reserves (adjusted by GDP); and degree of openness to trade. The second involves a descriptive analysis of the majority of the world's countries from 1980-2013 in terms of natural gas share of the energy mix and data on motivating factors towards natural gas, with a focus on several variables, including service industry proportion, manufacturing industry proportion, urbanisation and atmospheric pollution (including $\mathrm{PM}_{10}$ and $\mathrm{SO}_{2}$ ). 


\subsubsection{Various Approaches to Natural Gas Replacement}

\section{The seven benchmark countries primarily switched from oil to natural gas}

Each country uses oil, natural gas and coal in various proportions to satisfy its fossil fuel needs. As time passes, energy source structures gradually adjust. Figure 2.8 shows the fossil fuel energy mix changes over time in China and the benchmark countries. Each country's energy source structure change is shown as a pathway. The thin end represents the 1980 energy mix, and the thick end represents the 2012 energy mix. The energy mix change path follows the timeline from the thin end to the thick end.

If a country's path moves to the top of the triangle, this indicates that the share of natural gas increased in that country. If a country's curve moves away from "Oil" in the bottom left towards the top of the triangle, this indicates that natural gas replaced oil, as in Egypt (pink),
Turkey (purple) and Japan (green). If a country's path moves from away from "Coal" in the bottom right towards the top of the triangle, this indicates that coal had been replaced with natural gas in that country, as in United States (yellow) and the United Kingdom (blue). If the country's curve goes straight up toward the top of the triangle, then this indicates that natural gas has replaced both oil and coal in that country, such as in Germany over the past few years (grey). China's energy mix (red) has always been focused on coal, with only slight changes so far.

From Fig. 2.8 it is apparent that the countries with the fastest growth in demand for natural gas are those switching from oil to natural gas, whereas China is switching from coal to natural gas. To allow a conclusion to be reached that is of relevance to China, a large range of countries is required for comparison, in particular those that have converted from coal to natural gas, even if the scope of conversion to natural gas in these countries is smaller than that encountered in the seven benchmark countries.
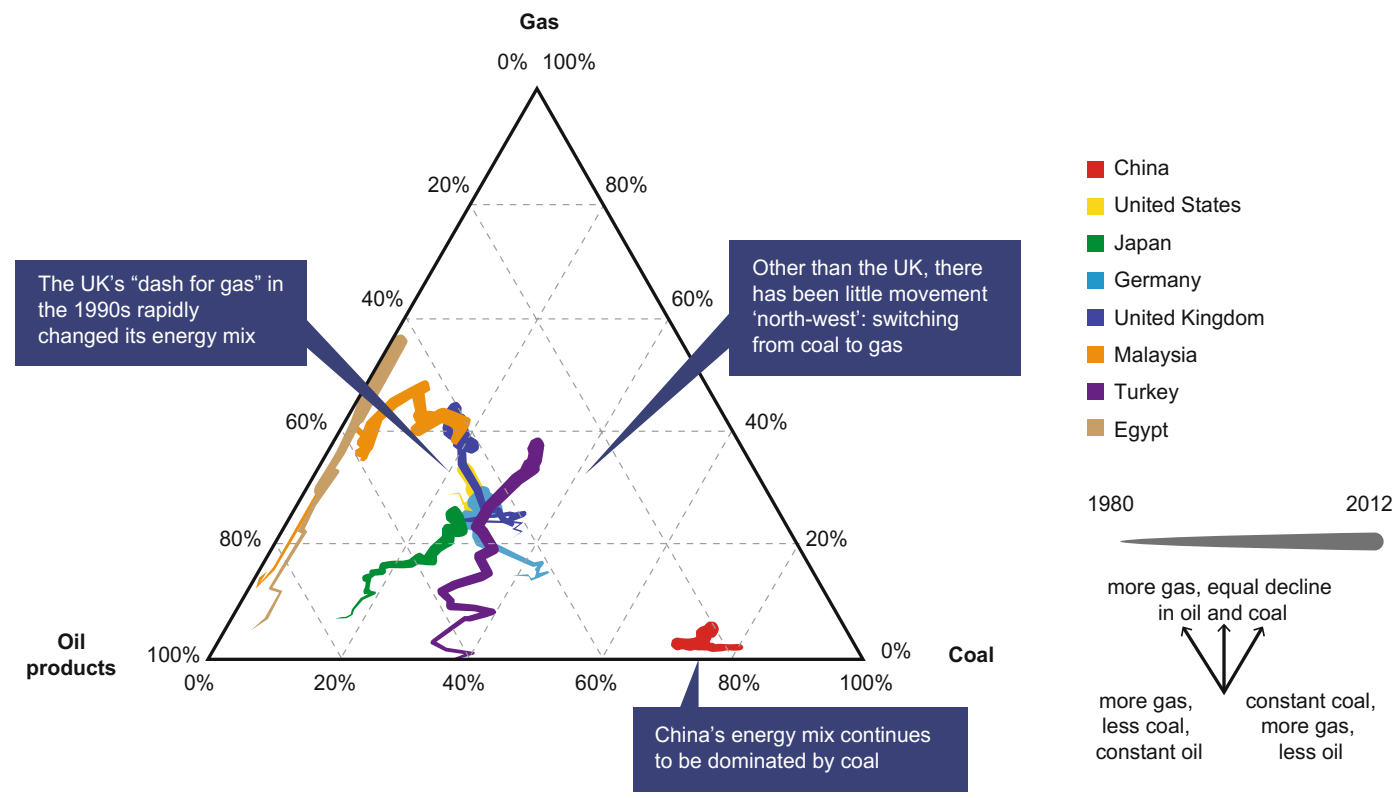

Fig. 2.8 Natural gas replacement pathways in China and benchmark countries (1980-2012). Source Formulated by Vivid Economics based on IEA data 
2. Main replacement pathways in countries transitioning from coal to gas

Conversion from coal to gas is mainly encountered in Europe, Australia and the United States. Figure 2.9 shows the changes in energy structure in terms of coal and natural gas for major countries that have transitioned from coal to gas. Curves running from the bottom right-hand corner represent a high percentage of coal, while movement toward the top left corner is toward a high percentage of natural gas. Developed countries, primarily in Europe, and especially the United Kingdom, have seen a high proportion of coal usage transition toward a high proportion of natural gas. From the perspective of overall global trends (orange pathway) in recent years relating to fossil fuels, coal proportions have seen some increase, primarily due to declines in oil rather than natural gas. The motivating factors for European countries to switch to natural gas may also be of relevance when considering switching from coal to gas in China.

\subsubsection{Analysis of Driving Factors in OECD Member Countries Switching to Natural Gas}

We conducted regression analysis on natural gas consumption proportions and other factors for OECD countries for 2012. The aim of this analysis was to identify the primary motivating factors behind OECD countries switching to natural gas.

Based on the regression results, there were four factors - service industry share, normalised GDP-adjusted total natural gas reserves, degree of openness to trade (a ratio between the import/export totals and GDP) and current natural gas reserves - that acted as major variables in

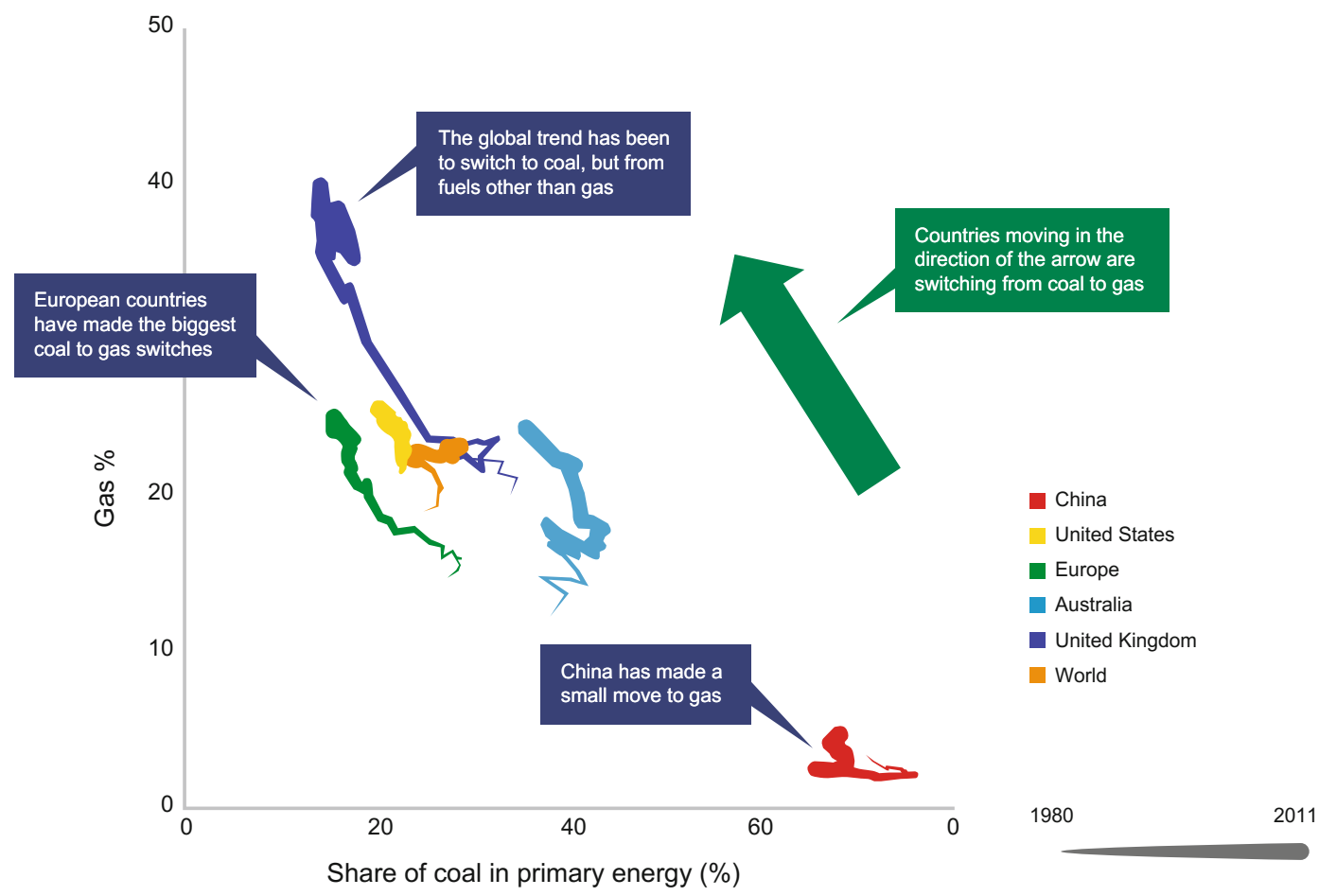

Fig. 2.9 Changes in energy usage from coal to natural gas. Note The data represents non-renewable energy source percentage; the data only shows countries that have experienced major transitions to gas. Source Formulated by Vivid Economics based on IEA data 
natural gas share in OECD countries. Changes in these four variables have a pronounced influence on natural gas share. For example, if a member country's service industry share changes by $1 \%$, then that country's natural gas proportion will change by $0.86 \%$ (Table 2.1 ). By conducting further computation, it can be deduced that these four variables are responsible for $53 \%$ of the changes in OECD member country natural gas share. That is to say, differences in OECD member countries' natural gas shares can mainly be traced back to these four variables.

When all factors are considered, service industry share is the factor that has the greatest effect on proportion of natural gas in OECD member countries. Figure 2.10 shows standard values for regression coefficients. By employing standard regression coefficients, one can compare the importance of such variables. The higher the standard value, the greater the importance.
Service industry share is the most important variable, followed by GDP-adjusted natural gas reserve levels. Based on these results, it is clear that service industry share is not only the most important variable, but is also an index that can be used as a yardstick for other driving factors. For example, countries with a larger service industry share could be at the stage of introducing increasingly strict controls on air quality, and this will further increase the market share of natural gas. However, this research does not incorporate air quality monitoring data; other variable factors that could explain natural gas share, such as urbanisation, were incorporated into the factors we considered, but did not affect the results. This is because by 2012 the majority of OECD member countries had already achieved a high degree of urbanisation, and thus there were no significant differences in urbanisation between them.

Table 2.1 Role of four variables in OECD country natural gas share

\begin{tabular}{|c|c|}
\hline Variable & An increase of $1 \%$ of any variable will cause: \\
\hline $\begin{array}{l}\text { Share of service industry } \\
\text { Gross value added in services sector }\left(\mathrm{GVA}_{\text {services }} /\right. \\
\text { GVA) }\end{array}$ & Natural gas share rises by $0.86 \%$ \\
\hline $\begin{array}{l}\text { Natural gas reserve levels (adjusted for normalised } \\
\text { GDP) } \\
\text { Reserve levels/GDP }\end{array}$ & Natural gas share rises by $0.49 \%$ \\
\hline $\begin{array}{l}\text { Degree of openness to trade } \\
\text { (Imports + Exports)/GDP }\end{array}$ & Natural gas share rises by $0.09 \%$ \\
\hline $\begin{array}{l}\text { Whether there are natural gas reserves or not } \\
1 \text { represents entirely no reserves, } 0 \text { represents the }\end{array}$ & $\begin{array}{l}\text { If a country does not have natural gas reserves, then natural } \\
\text { gas share drops } 0.15 \%\end{array}$ \\
\hline
\end{tabular}
existence of reserves

Note This cross-sectional regression analysis uses 2012 data Source Vivid Economics

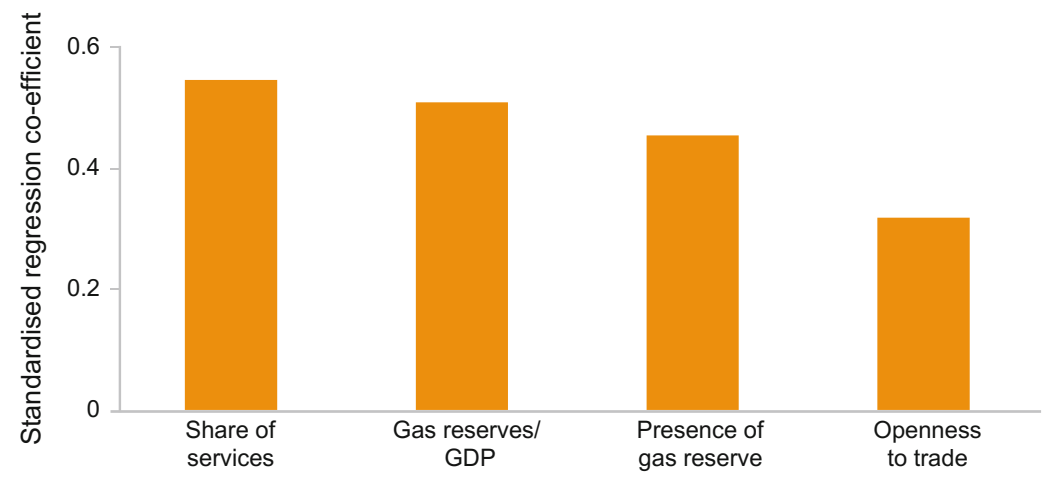

Fig. 2.10 Regression results for 2012 natural gas share in OECD countries 
The OECD country analysis results show that when a country has natural gas reserves and has already entered the stage of development in which services are the primary focus, natural gas accounts for a very large share of the energy mix. Domestic reserves are undoubtedly important, because those reserves are often a country's cheapest source of natural gas and, regardless of how extensive they are, they will influence the natural gas share. This implies that countries without natural gas reserves might not make natural gas a primary energy source, that natural gas would not be used for infrastructure and by institutions, and that the import of natural gas would not be encouraged. The OECD countries South Korea and Japan are an exception to this, though; their domestic natural gas reserves are negligible, they have a high degree of openness to trade and they restrict other energy sources, which results in natural gas having a relatively high share in their energy structures.

The analytical data shows the influence of factors driving changes in the use of natural gas in developed countries, but does not consider the effects of urbanisation and atmospheric pollution. These factors are of major relevance in China, but they are less influential in OECD member countries. The next section will therefore expand the range of countries looked at so that a more comprehensive range of driving factors can be examined.

\subsubsection{Further Analysis of Motivating Factors for a Country to Switch to Natural Gas}

To further analyse the factors motivating a country to switch to natural gas, we carried out a comparison of data on natural gas share and natural gas motivating factors for most of the world's countries for the period 1980-2013. This permitted a more comprehensive analysis of how changes in each country's natural gas share correlated with changes in the variables. A global dataset was built for the years 1980-2013, including natural gas share, service industry share, manufacturing share, urbanisation and atmospheric pollution including $\mathrm{PM}_{10}$, and $\mathrm{SO}_{2}$ for each country. The changing trends are outlined in Figs. 2.11, 2.12, 2.13, 2.14, 2.15 and 2.16 .

\section{Apart from China, service industry share is often closely connected to natural gas share}

Changes in service industry share and natural gas share exhibit the same trends. In other words, when one variable changes, the other variable changes along with it. This kind of common trend suggests that a connection exists between the two and all that remains is for it to be confirmed by statistical analysis. There is a pronounced pattern in the United Kingdom, Japan and South Korea, and many other countries also exhibit such characteristics. In Fig. 2.11, only the data from China fails to demonstrate a relationship between service industry share and natural gas share. Nonetheless, China's service industry share is similar to levels in Japan and South Korea in 1980, so it is likely that this trend will manifest in the future.

\section{The relationship between the manufactur- ing industry share and natural gas share is not pronounced}

Only in a minority of countries is there a connection between manufacturing share and natural gas share; in the majority of countries the two do not have a pronounced relationship. Figure 2.12 shows that, with the exception of China, Asia's emerging markets all use natural gas to develop their manufacturing industries. In Europe, the natural gas share continues to rise as deindustrialisation proceeds. This implies that the relationship between manufacturing industry share and natural gas share could change depending on industrial and energy mix policies, as well as changing as a result of economic development. 


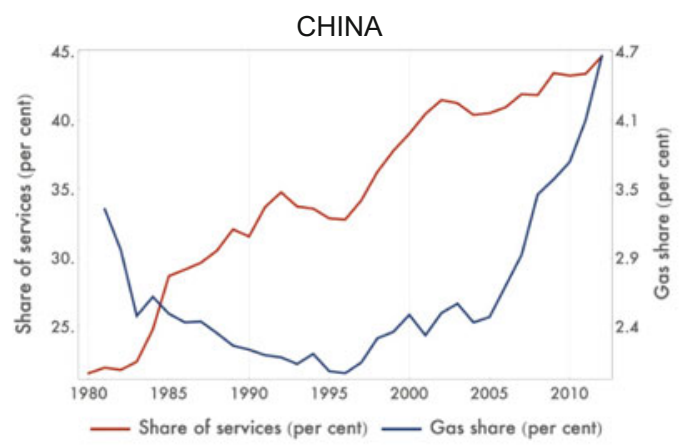

UNITED KINGDOM

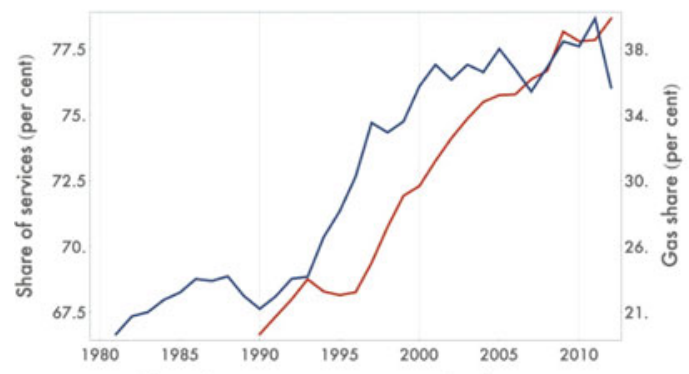

- Share of services (per cent) - Gas share (per cent)
INDIA

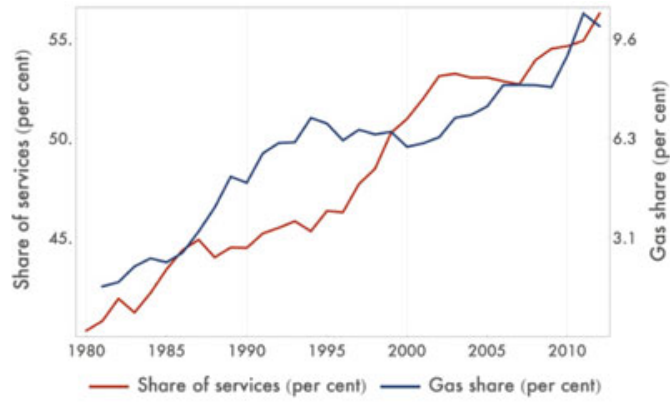

SOUTH KOREA

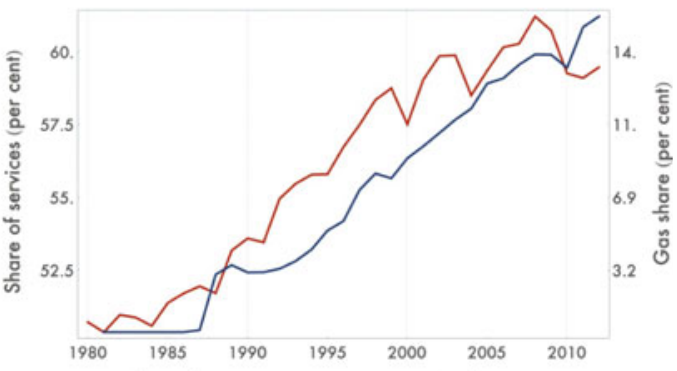

- Share of services (per cent) - Gas share (per cent)

Fig. 2.11 Size of service industry and natural gas share of energy mix, 1980-2010. Note Natural gas share refers to the share of natural gas within total non-renewable energy sources. Source Vivid Economics, based on EIA and World Bank data

CHINA

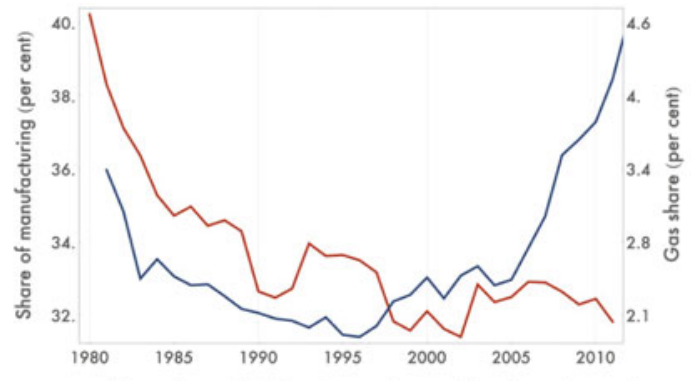

— Share of manufacturing (per cent) — Gas share (per cent)

UNITED KINGDOM

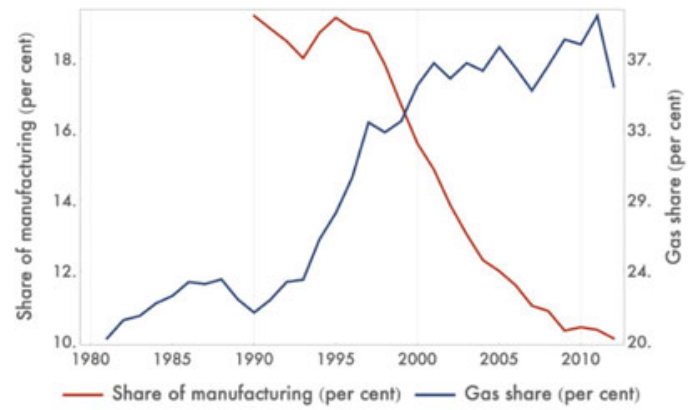

MALAYSIA

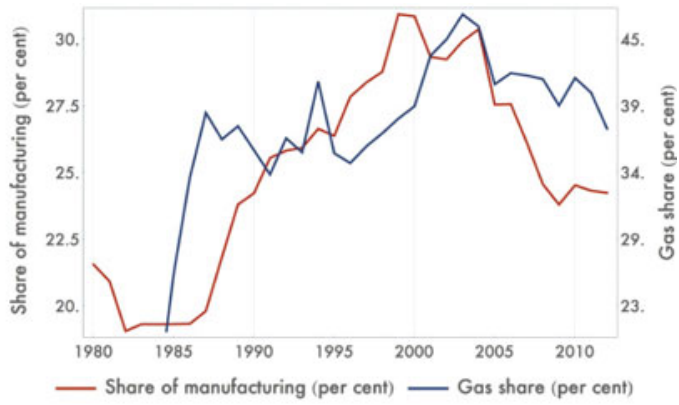

SOUTH KOREA

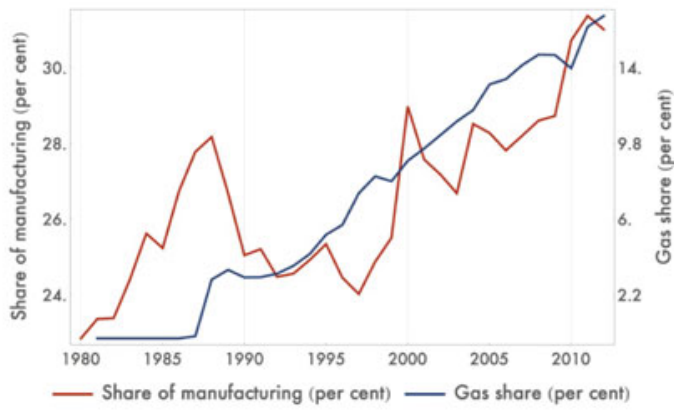

Fig. 2.12 Size of manufacturing industry and natural gas share of energy mix, 1980-2010. Note Data is for share of gas in primary energy. Source Vivid Economics, based on EIA and World Bank data 


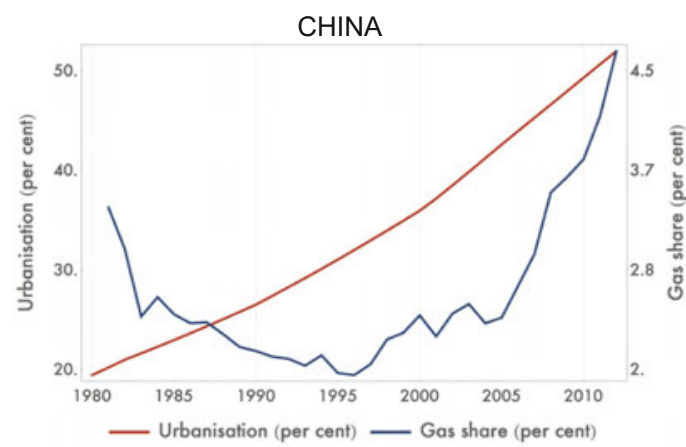

ARGENTINA

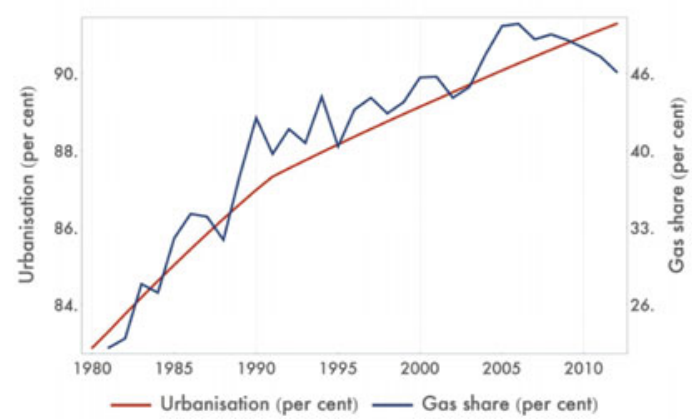

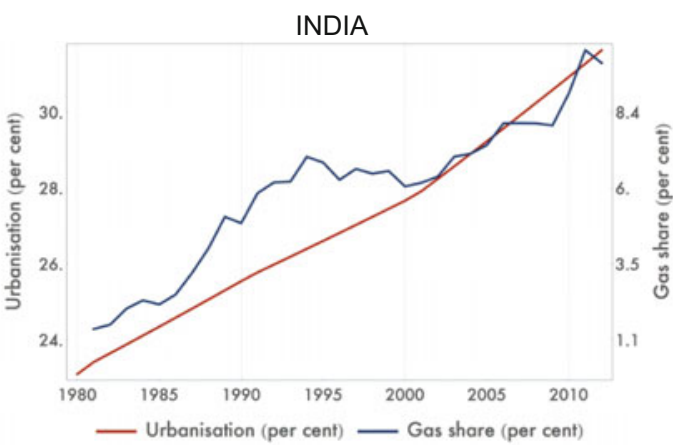

SOUTH KOREA

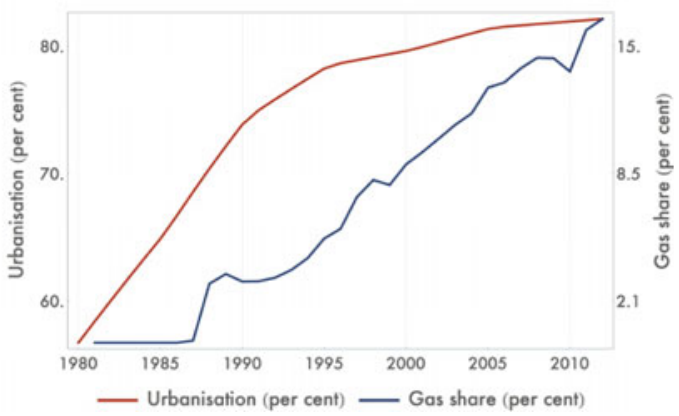

Fig. 2.13 Urbanisation and natural gas share of energy mix, 1980-2010. Note Data is for share of gas in primary energy. Source Vivid Economics, based on EIA and World Bank data

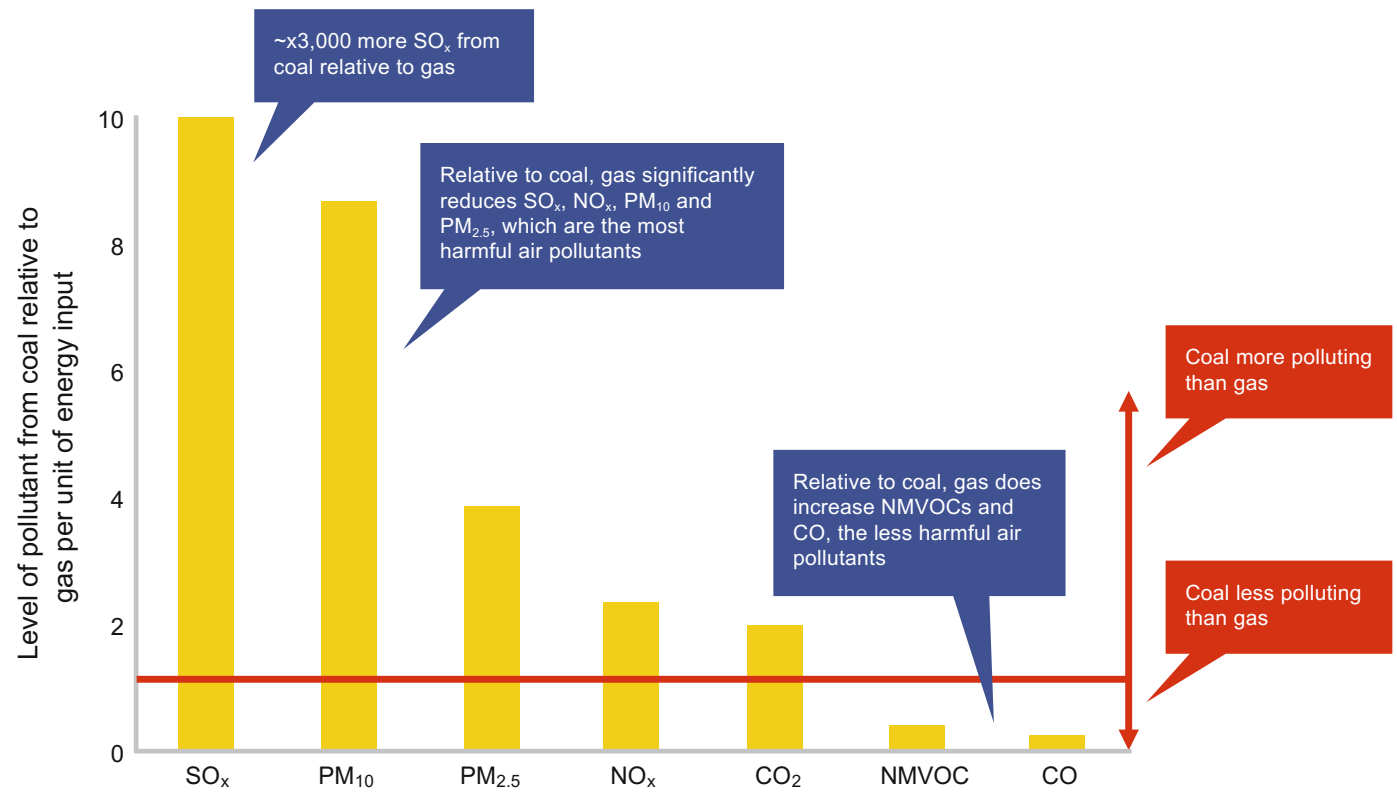

Fig. 2.14 Comparison of pollution resulting from natural gas power generation and from coal power generation, per unit calorific value. Source Formulated by Vivid Economics based on EEA and UNFCCC data 

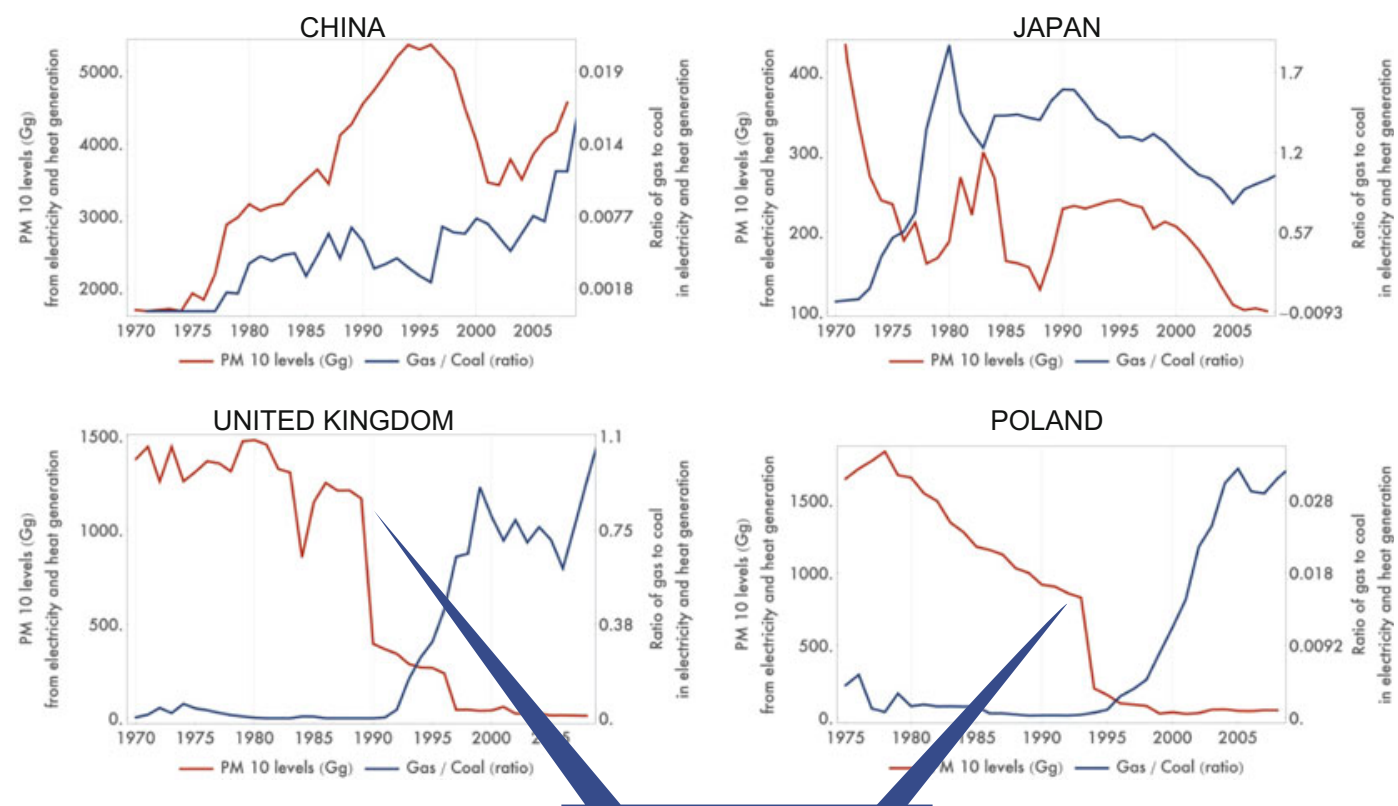

Pollution limits imposed, with entry

of gas in following years

Fig. 2.15 $\mathrm{PM}_{10}$ emission levels and natural gas share of heat and power generation, 1970-2010. Source Formulated by Vivid Economics based on EEA and UNFCCC data

\section{CHINA}

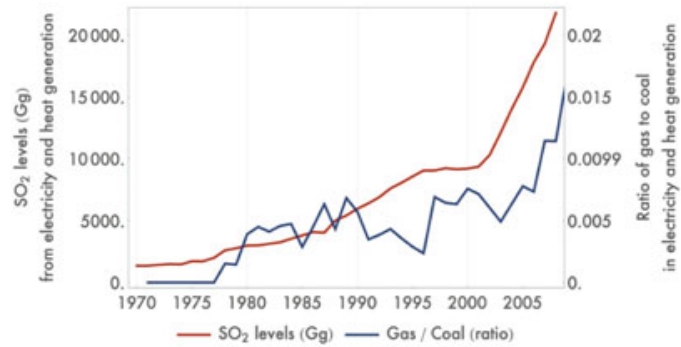

UNITED KINGDOM

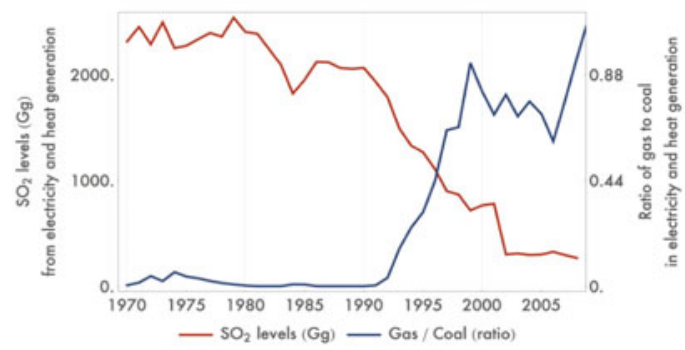

UNITED STATES

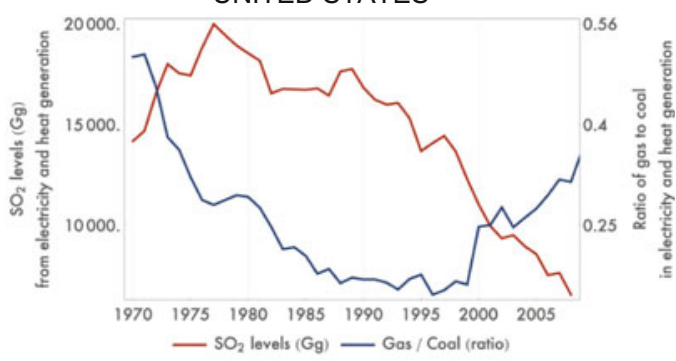

POLAND

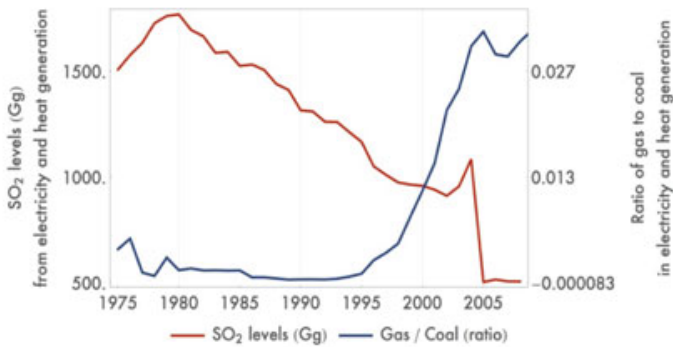

Fig. 2.16 Relation between power generation, $\mathrm{SO}_{2}$ emission levels and natural gas share of heat and power generation, 1970-2010. Source Formulated by Vivid Economics based on EEA and UNFCCC data 


\section{Urbanisation and natural gas share are closely related}

Urbanisation is closely related to natural gas usage, and China is now in the early stages of urbanisation. From Fig. 2.13 it can be seen that urbanisation and natural gas share are closely related in many countries. This is very likely due to the fact that natural gas is particularly well suited to use as a fuel in urban environments, since it is easily transported via networks of pipes, its combustion is easily controlled and it generates minimal atmospheric pollution. This is very important to an area with a high population density. So far, China does not exhibit this trend in the same way as other countries, but because China is in the early stages of urbanisation, greater demand for natural gas may result as urbanisation progresses.

\section{Many countries switch from coal to natural gas after enacting air quality legislation}

Compared to coal, natural gas is a comparatively clean fuel. For example, when power generation with natural gas is compared to power generation with coal, natural gas only results in small amounts of the most harmful air pollutants (Fig. 2.14). Many countries have therefore switched from coal to gas after air quality legislation is introduced.

\section{In countries where there are competitive power markets, the natural gas power generation share increases after $\mathbf{P M}_{10}$ re- strictions are put in place}

Figure 2.15 shows that in the United Kingdom and Poland, $\mathrm{PM}_{10}$ emissions generated by power generation dropped significantly in the year in which air quality legislation was introduced. Furthermore, the share of natural gas power generation then increased rapidly. This shows that in the completely competitive power markets of the United Kingdom and Poland, even though efforts were made to restrict $\mathrm{PM}_{10}$ emissions by other courses of action, the cost of coal power generation eventually became prohibitive and power generation began its transition to natural gas. Figure 2.15 also shows that in Japan, where the power generation market is more regulated, the increase in the share of natural gas power generation has not lagged behind changes in $\mathrm{PM}_{10}$, though there was also a marked direct effect in the 1970s, which shows that natural gas can be used directly to control atmospheric pollution. In China, even though the share of natural gas power generation is increasing, the total remains relatively small, and coal power generation's overwhelming growth suggests that the $\mathrm{PM}_{10}$ levels are set to remain elevated.

Figure 2.16 shows that in the United Kingdom, the United States, Poland and other countries, $\mathrm{SO}_{2}$ emission levels improved significantly after air quality legislation was enacted. The direction taken by changes to $\mathrm{SO}_{2}$ emissions may be similar to that for $\mathrm{PM}_{10}$ emissions, but the rate of reduction is slower. For coal-fired power stations, compared to satisfying the restrictions on $\mathrm{PM}_{10}, \mathrm{SO}_{2}$ restrictions will only be met successfully if they are adopted at a more gradual pace. In China, the enormous expansion of coal-fired power stations means that $\mathrm{SO}_{2}$ levels are set to remain high.

Many countries have implemented strategies to improve air quality by switching to natural gas. Analysis reveals that the approaches to implementing such strategies differ from country to country. Some countries rely on market forces and pollution control measures which force up the cost of coal, causing a transition to gas. Other countries adopt natural gas development planning. The ultimate result of these different approaches to controlling air quality is essentially the same, but the results in terms of controlling atmospheric pollution become apparent at different stages.

\subsubsection{Summary}

The main conclusions that can be drawn from our analysis of the drivers for transition to natural gas are that, in the course of development, an increase in the size of the service sector, the pressures of urbanisation and an urgent need to control atmospheric pollution result in all countries switching gradually to natural gas. Major 
adjustments have been made in Europe, the United States and Australia in switching from coal to natural gas - and this now also needs to occur in China. At first glance, these adjustments are a result of a growing service sector share driving an increase in demand for natural gas, but there is also evidence that other trends drive demand for natural gas, such as urbanisation and demands for cleaner air. These two factors play a major role in the motivating the transition in many countries. As urbanisation in China proceeds, an increasing amount of attention is being paid to air quality, and this is likely to encourage greater use of natural gas.

\subsection{The Influence of Natural Gas Price on Demand}

As well as factors such as service sector growth, urbanisation and air quality controls, natural gas price also has a direct effect on energy costs, and can play an important role in affecting demand. This section carries out an in-depth analysis of the relationship between natural gas price and demand. The analysis mainly concentrates on the experiences of OECD countries, because as they are the primary natural gas-consuming countries, there is relatively good data available. Furthermore, in the majority of cases, these countries have liberalised energy price markets, making it easier to follow the changes in natural gas pricing, and easier to analyse the relationship between pricing and demand.

\subsubsection{The Relationship Between Natural Gas Price Changes and Changes in Demand in OECD Countries Is not Pronounced}

\section{Natural gas demand in OECD countries grew rapidly from relatively low levels between 1987 and 2000}

Figures 2.17, 2.18, 2.19 and 2.20 show the evolutionary progress of natural gas prices and the demand of main sectors in the United Kingdom, the United States, Japan and Germany. Each point represents data for a year. The colours of the points represent annual rates of change in natural gas demand. The vertical axis plots the natural gas price to industry, with prices expressed as 2010 PPP (purchasing power parity - that is, including inflation and relative price change adjustments). This price thus represents changes in natural gas affordability. There is a clear increase in natural gas prices during the early 1980 s, with a drop in 1987 . Since then they have remained fairly stable until 2000. Subsequently, and in particular from 2005 until the Global Financial Crisis and the shale natural gas revolution in the United States, prices have risen continuously. Although industry sector gas prices are considered, it seems that they have increased at the same rate - the price of residential gas is higher than that used by industry.

Based on the experience of four countries, natural gas prices between 1987 and 2000 were low and stable and yet, compared to other periods, natural gas demand continued to grow rapidly. During this period, the number of years when there was higher growth in sector demand for natural gas was greater than in the period when the price was higher. For example, Japan and the United Kingdom saw more years with increased demand during this period than at other times (tending towards red on the scale).

\section{Natural gas demand rose in many coun- tries when natural gas prices were high}

Even though natural gas prices began to rise in 2000, in the United Kingdom, Japan and Germany, demand for natural gas remained consistently steady or grew. From 2000 to 2008, natural gas prices in OECD countries actually rose by $60 \%$. Despite this, during the overlapping period of 2000-2012, industrial and residential natural gas demand in OECD countries only dropped by $8 \%$. This indicates that, once demand stabilises, it is capable of withstanding wide economic fluctuations. This could be due to the fact that natural gas demand is not sensitive to price changes (i.e. it is non-elastic), at least in 


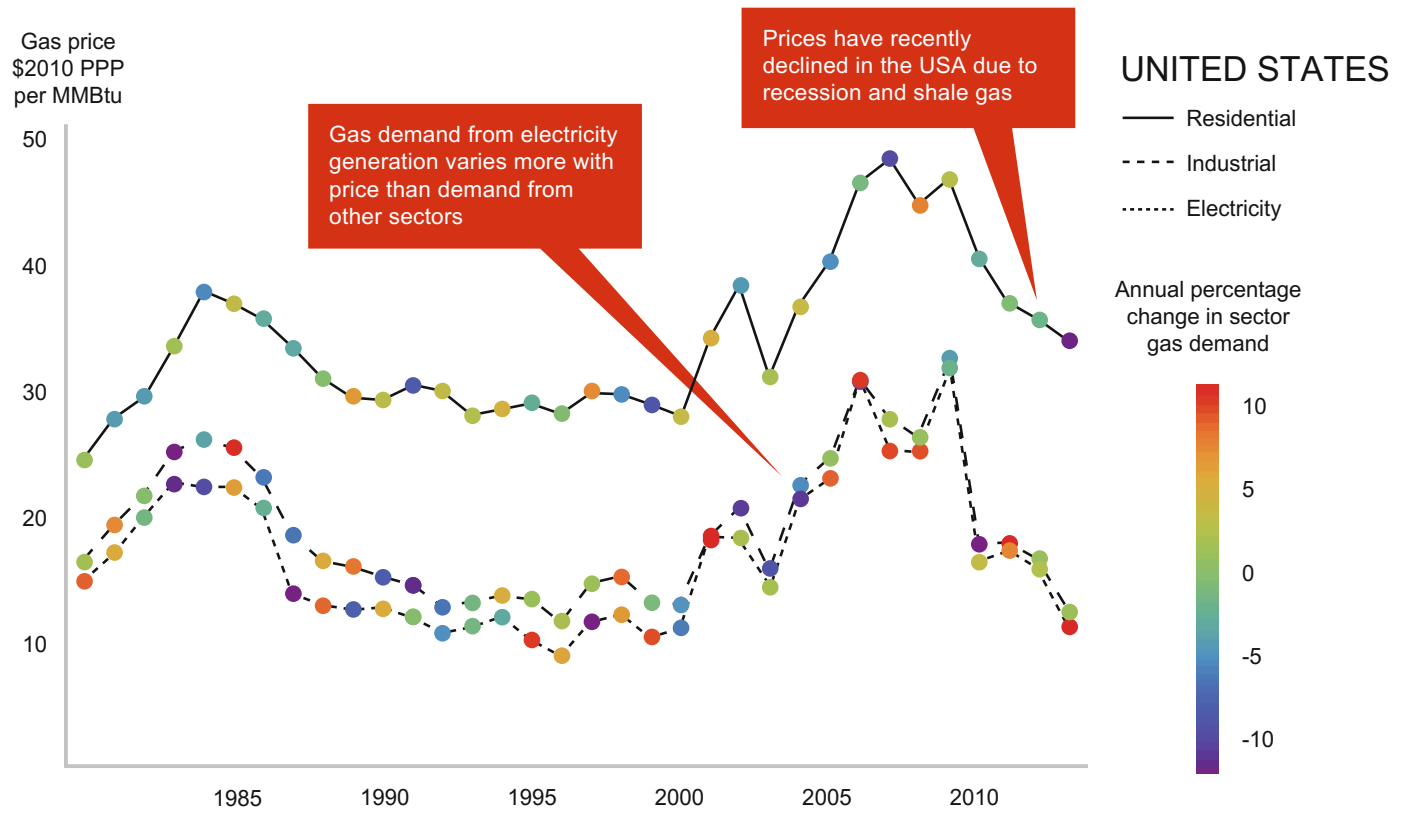

Fig. 2.17 Relationship between growth in demand for natural gas and pricing in three sectors in the United States. Source Vivid Economics based on IEA data

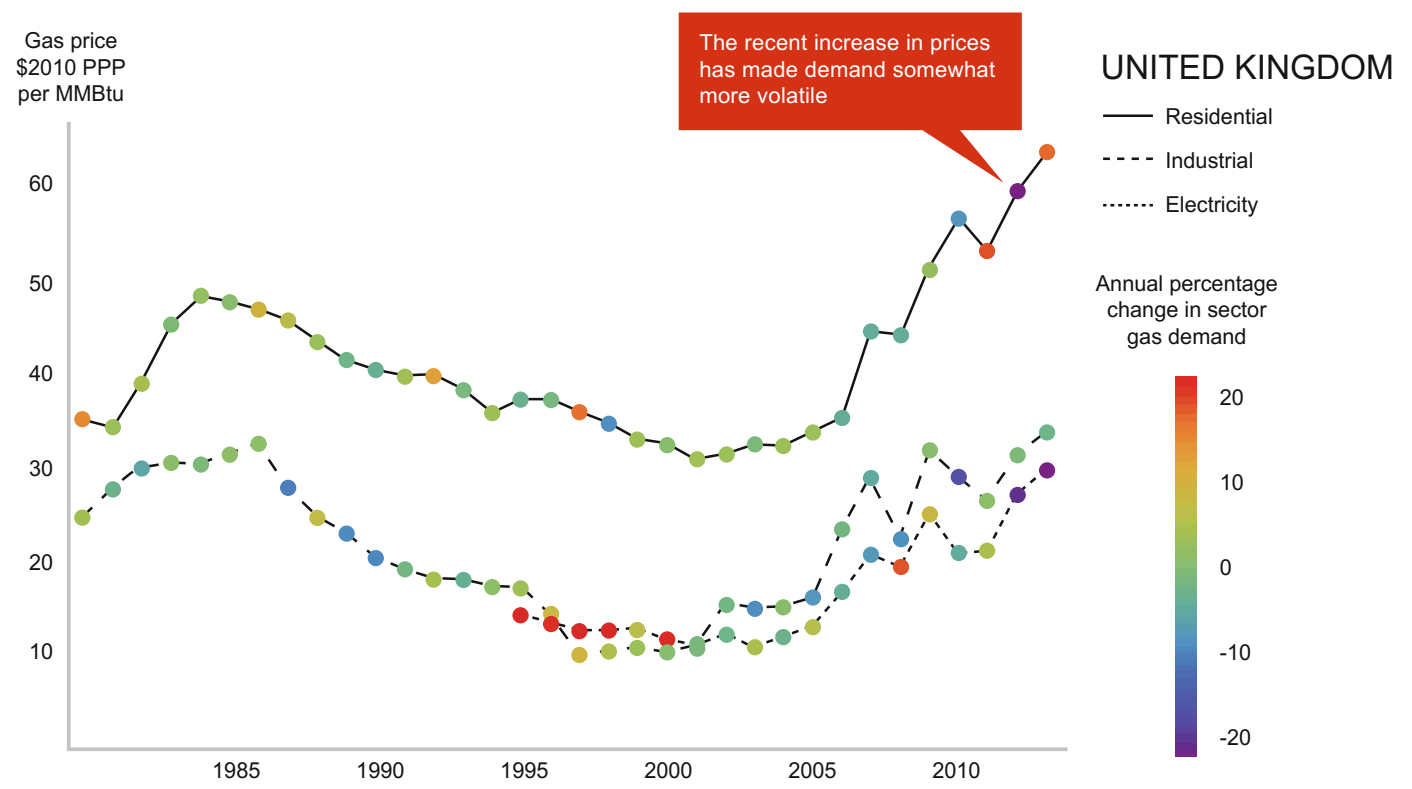

Fig. 2.18 Relationship between growth in demand for natural gas and pricing in three sectors in the United Kingdom. Source Vivid Economics, based on IEA data

terms of residential usage. Moreover, once natural gas is adopted, residents are not willing to give up natural gas for other fuels. As a clean fuel, allowing controllable heating and with easily accessible exothermic properties, when natural gas is compared to other fuel types, such as coal, it becomes apparent that due to its individual properties, as soon as the necessary 


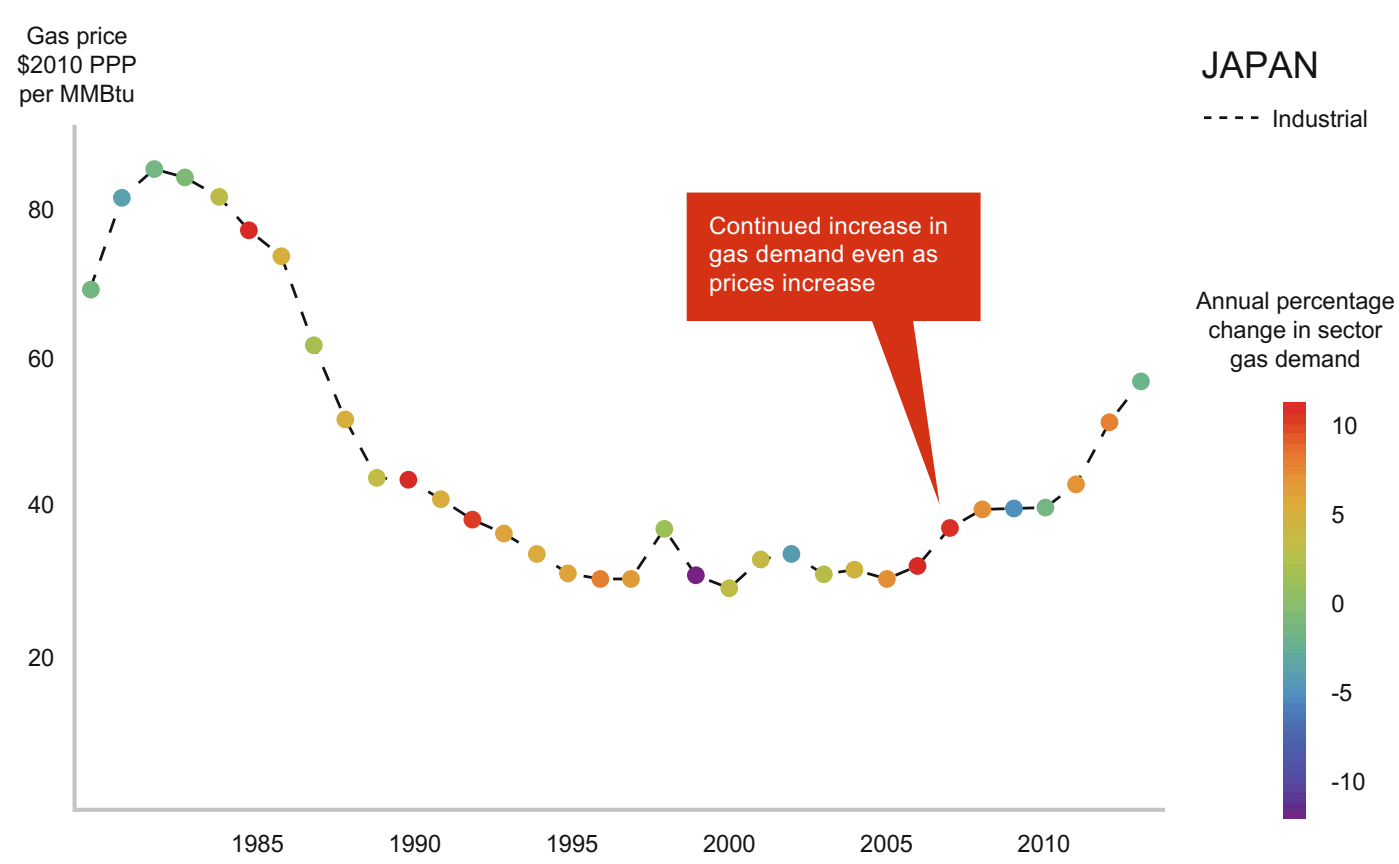

Fig. 2.19 Relationship between growth in demand for natural gas and pricing in industry in Japan. Source Vivid Economics, based on IEA data

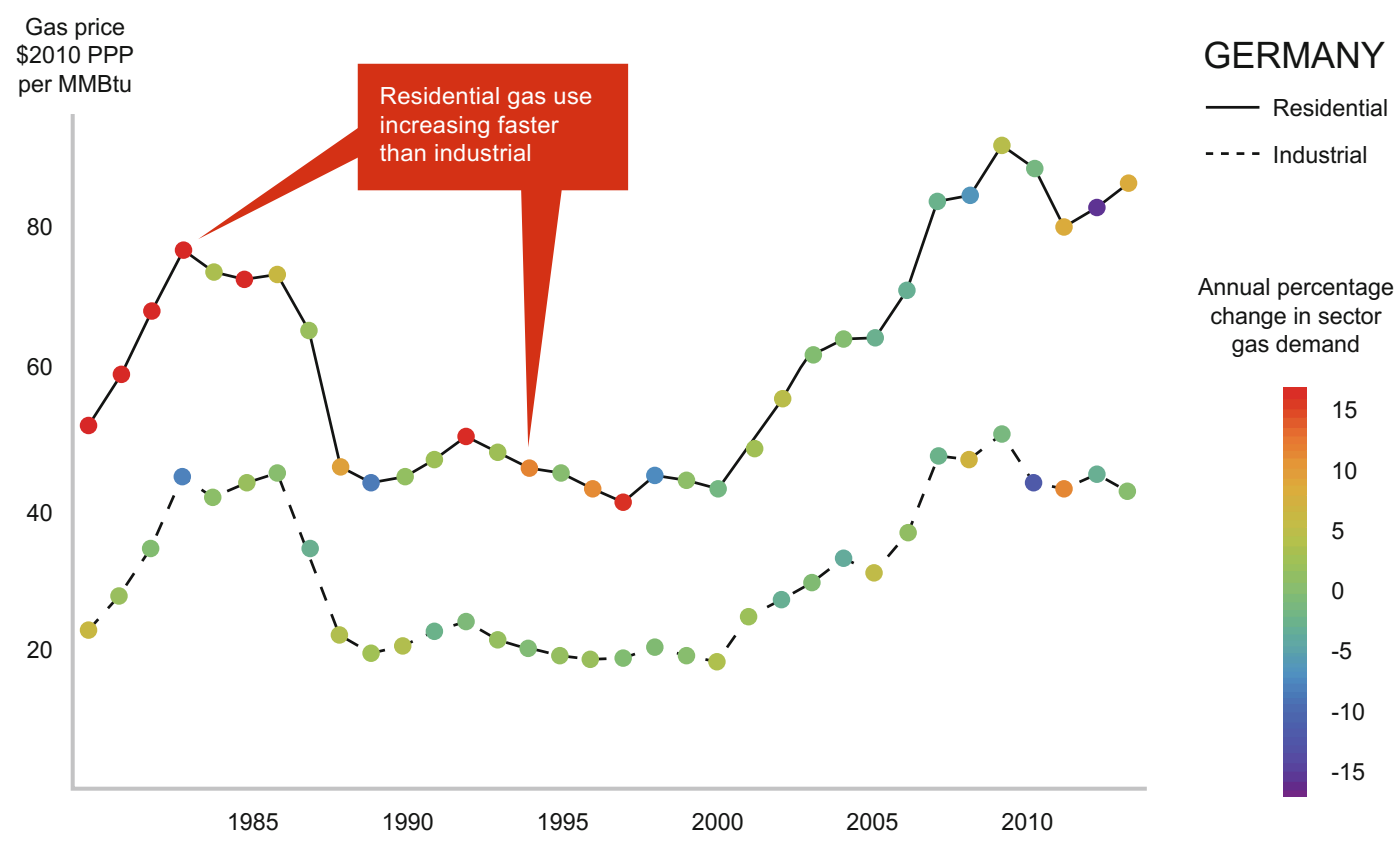

Fig. 2.20 Relationship between growth in demand for natural gas and pricing in the residential and industrial sectors in Germany. Source Vivid Economics, based on IEA data 
infrastructure is in place, residents and manufacturers are less concerned about price. From these observations we can see a kind of "ratchet effect": once natural gas demand reaches a certain level, the likelihood of switching to another energy source is lower, therefore there is less likely to be a reduction in demand. Only scientific innovations such as electric heat pumps, that may be capable of offering even higher-quality heat and efficiency, will change the current "non-elastic" state of affairs.

On the whole, during periods when natural gas prices are rising, increases in demand for natural gas from manufacturing, residential and power generation sectors seem to keep step. Despite a lack of data covering all industries in all countries, the data that is available shows that demand for natural gas generally increases across the board in all sectors. Although this is not applicable to the United States, the United Kingdom, Japan and Germany, it is still applicable to other major natural gas-consuming countries such as The Netherlands and Spain.

\section{No pronounced relationship between sec- tor gas price and demand share}

Figure 2.21 shows natural gas PPP price against overall demand share in various sectors for OECD countries in 2012. This shows that there is no pronounced relationship between sector gas price and demand share in each country; although the industrial sector gas price in some of these countries is relatively low, the industrial sector gas demand share in those countries is not necessarily high.

From Fig. 2.21 it is also possible to see that the price of residential sector gas in OECD countries is relatively high, with residents willing to pay higher gas charges. This could be because residential natural gas usage requires the economies of scale, since the transportation and delivery costs are much higher. Practically speaking, there is no pronounced relationship between residential demand and gas price, since the primary replacement energy source for residential usage is electricity. Electricity is relatively more expensive, and natural gas is more convenient. In fact, the high price of natural gas doesn't seem to have had a negative impact on residential demand for natural gas. Over recent years there has been a greater increase in demand for gas for residential use than for industrial use in OECD countries.

\subsubsection{Limited Effect on Demand of Difference in Price Between Natural Gas and Other Energy Sources}

Economically speaking, the demand for a particular item is not only determined by its price, but also by the price of alternatives. This suggests that

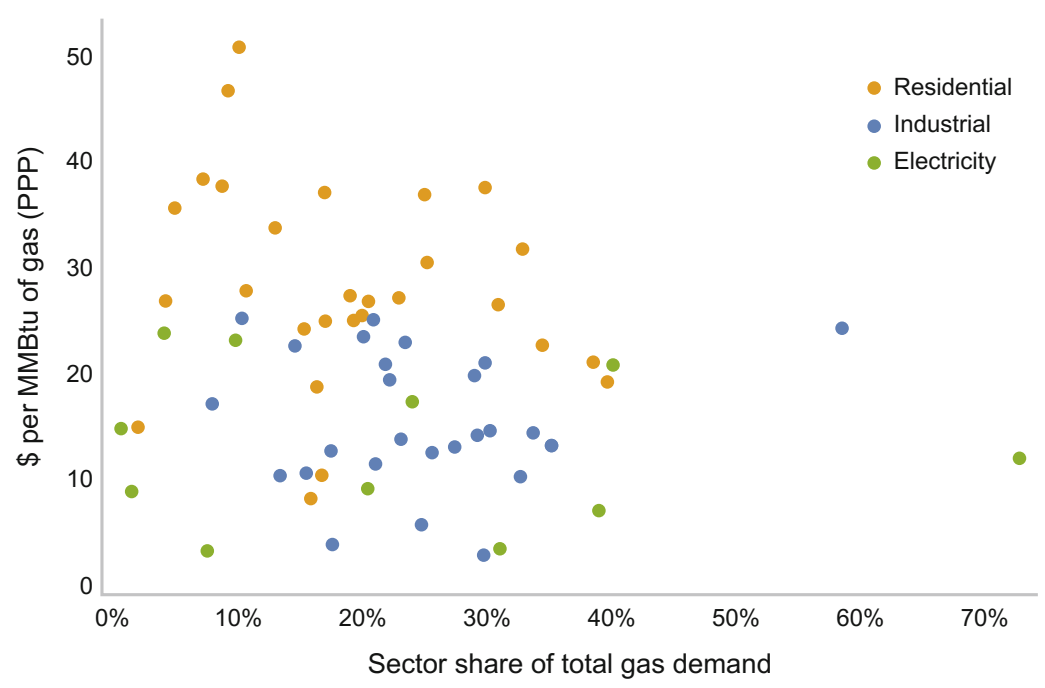

Fig. 2.21 Relationship between sector gas price and share in OECD countries (2012). Source Vivid Economics, based on IEA data 
natural gas demand will also be affected by the difference in price between natural gas and other energy sources.

\section{The difference in price between natural gas and electricity in OECD countries has not affected the demand for gas in the indus- trial and residential sectors}

In OECD countries, the natural gas price is lower than that of electricity in both residential and manufacturing sectors. Compared to countries where the price of electricity is lower than that of natural gas, natural gas has a slightly higher share of primary energy sources, though this effect is still not all that pronounced. Figures 2.22 and 2.23 show the relationship between the pricing of natural gas and electricity in different countries and the natural gas share in the industrial and residential sectors. The dots in the diagram represent different countries, while the colour of the dots indicates natural gas share.

Figure 2.22 shows the residential sector, while Fig. 2.23 shows the manufacturing sector. These two diagrams demonstrate that pricing competition between the residential and manufacturing sectors has very little influence on demand for natural gas or electricity.

\section{Rate of growth in demand for natural gas in OECD countries was especially rapid during a period of stable relative energy source prices}

From 1987 to 2000, demand for natural gas in OECD countries grew rapidly. However, during that period the prices of natural gas, electricity and coal remained relatively stable. Figures 2.24 and 2.25 both indicate this situation. For example, during this period, looking at the actual unit price of energy in the manufacturing sector, the mean gas price was only $22 \%$ of the electricity price, or around one quarter. However, compared to the price of coal, the price of natural gas was over three times higher, at around $320 \%$. When relative prices remain stable, the competitiveness of each energy source remains unchanged, and thus demand will not change as a result of pricing competition between energy sources. However, it was under precisely such circumstances that natural gas demand nevertheless grew steeply, an indication that factors other than price play a

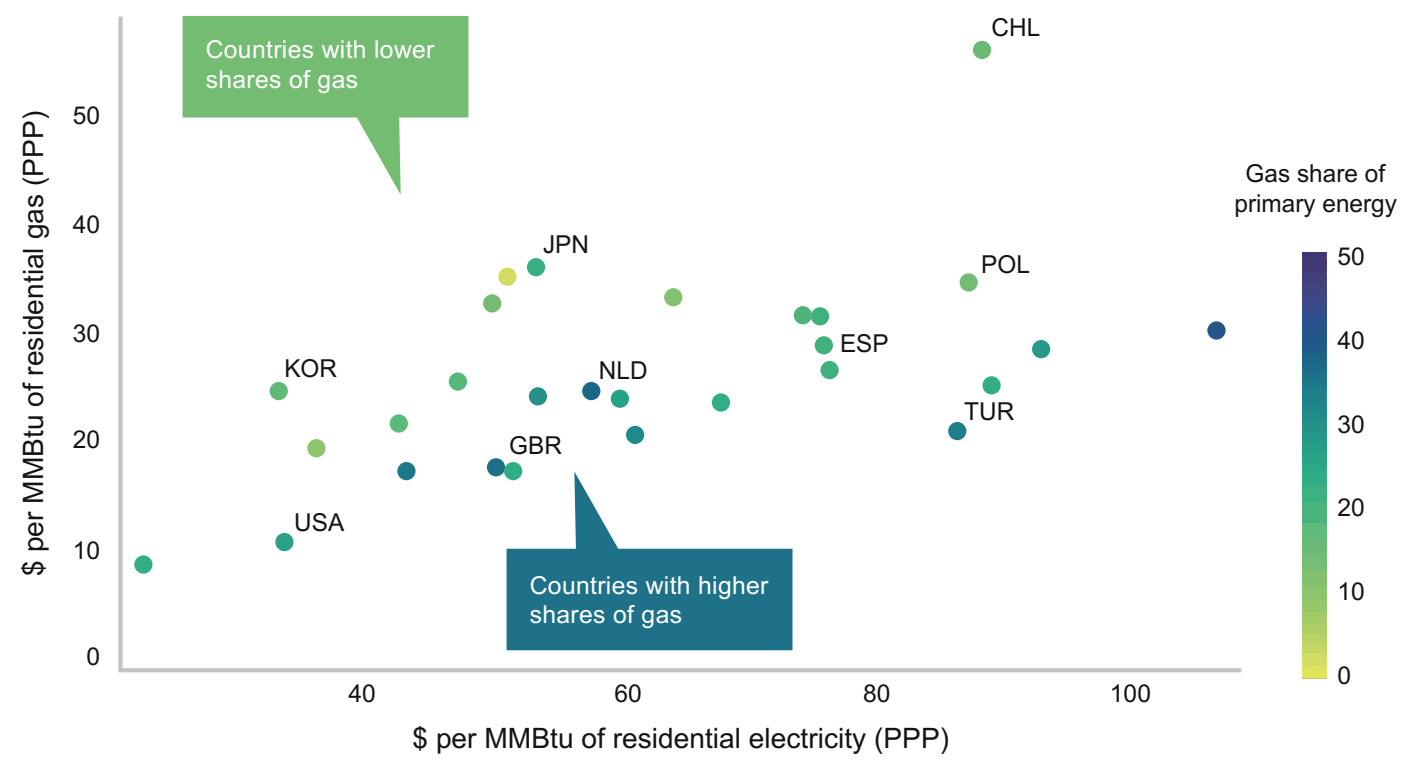

Fig. 2.22 Residential gas share and pricing differences between gas and electricity. Note Data is for 2012, electrical units have been converted from MWh to MMBtu. Source Vivid Economics, based on IEA data 


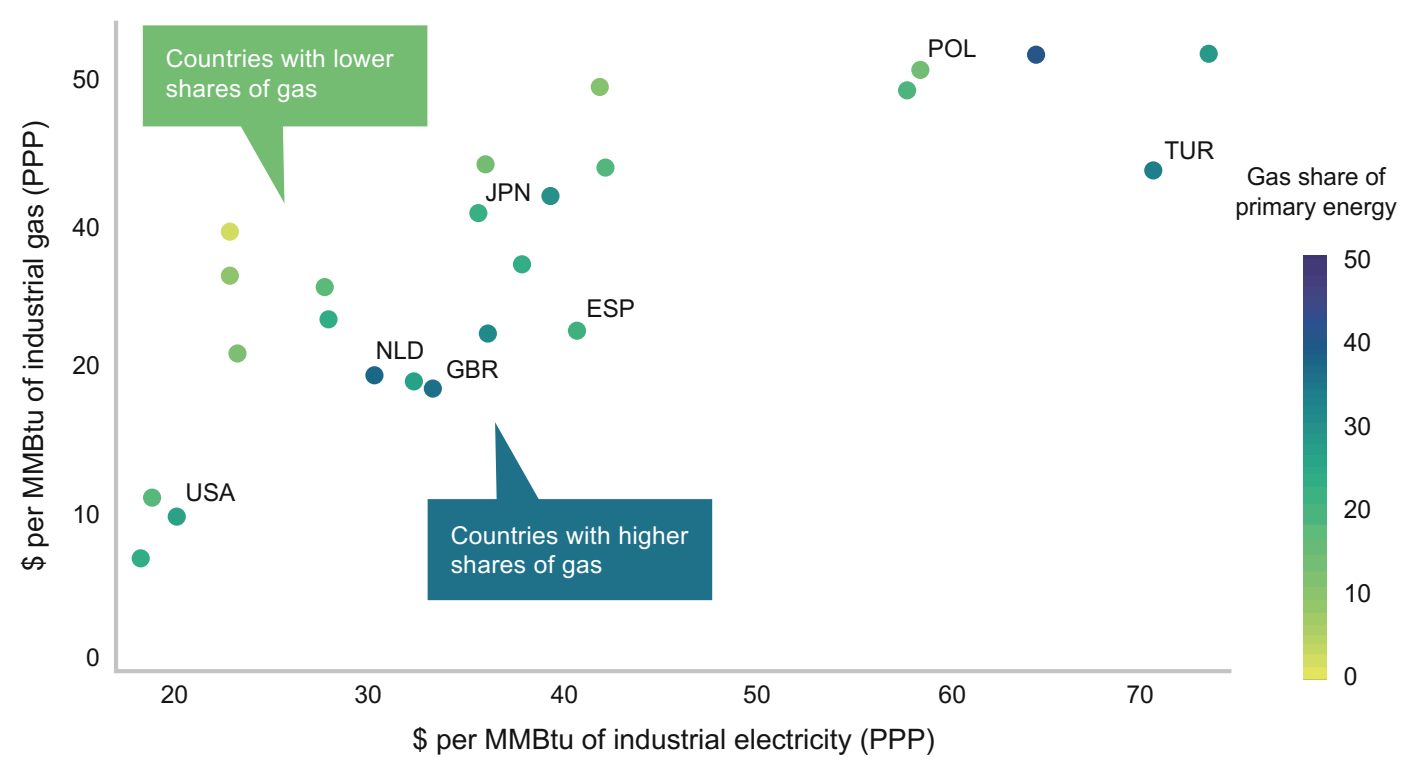

Fig. 2.23 Industrial sector natural gas proportion and variance in natural gas and electricity price. Note Data is for 2012, electrical units have been converted from MWh to MMBtu. Source Vivid Economics, based on IEA data

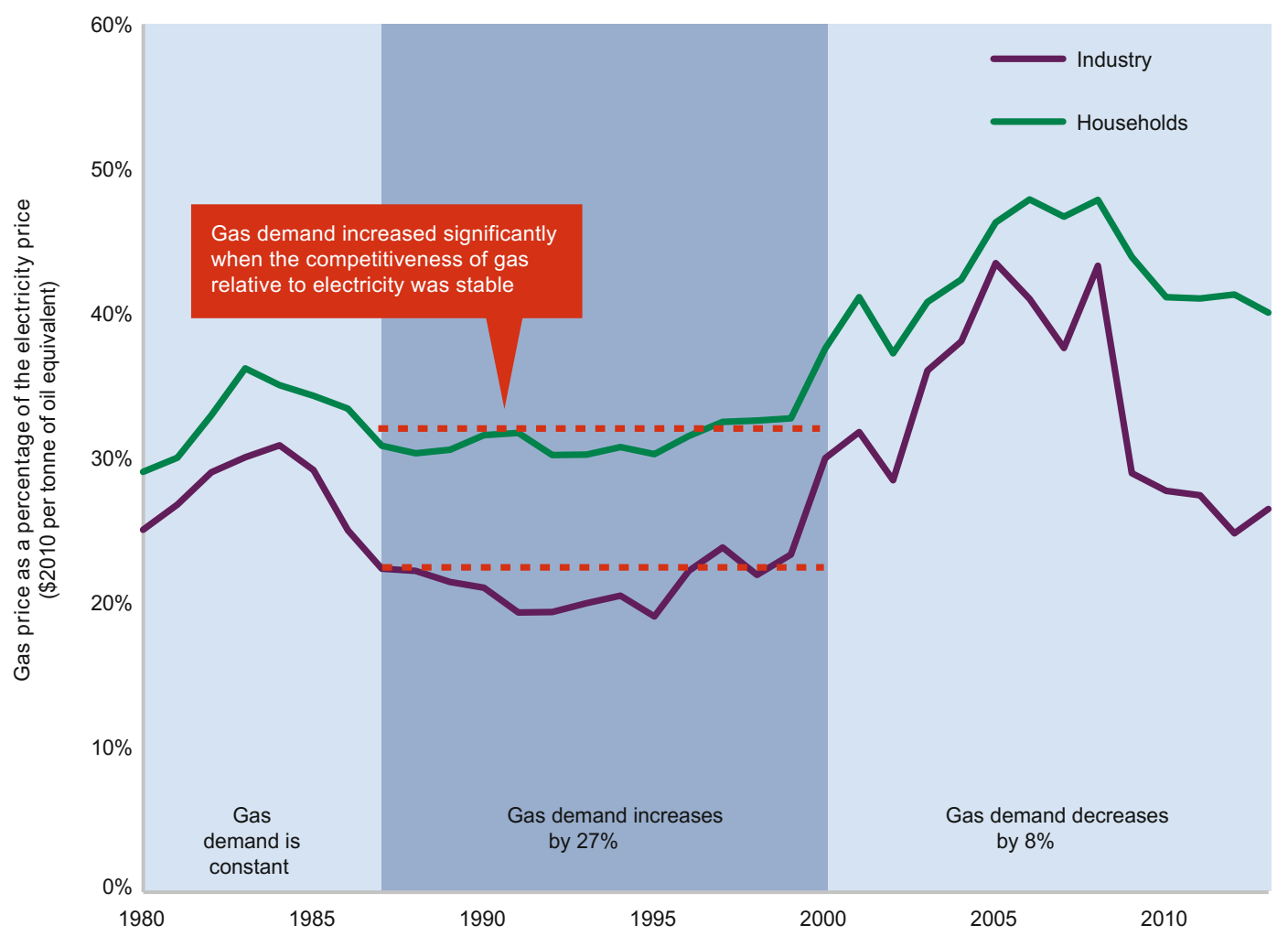

Fig. 2.24 Natural gas and electricity price difference and demand growth. Data source Vivid Economics quoting the IEA 


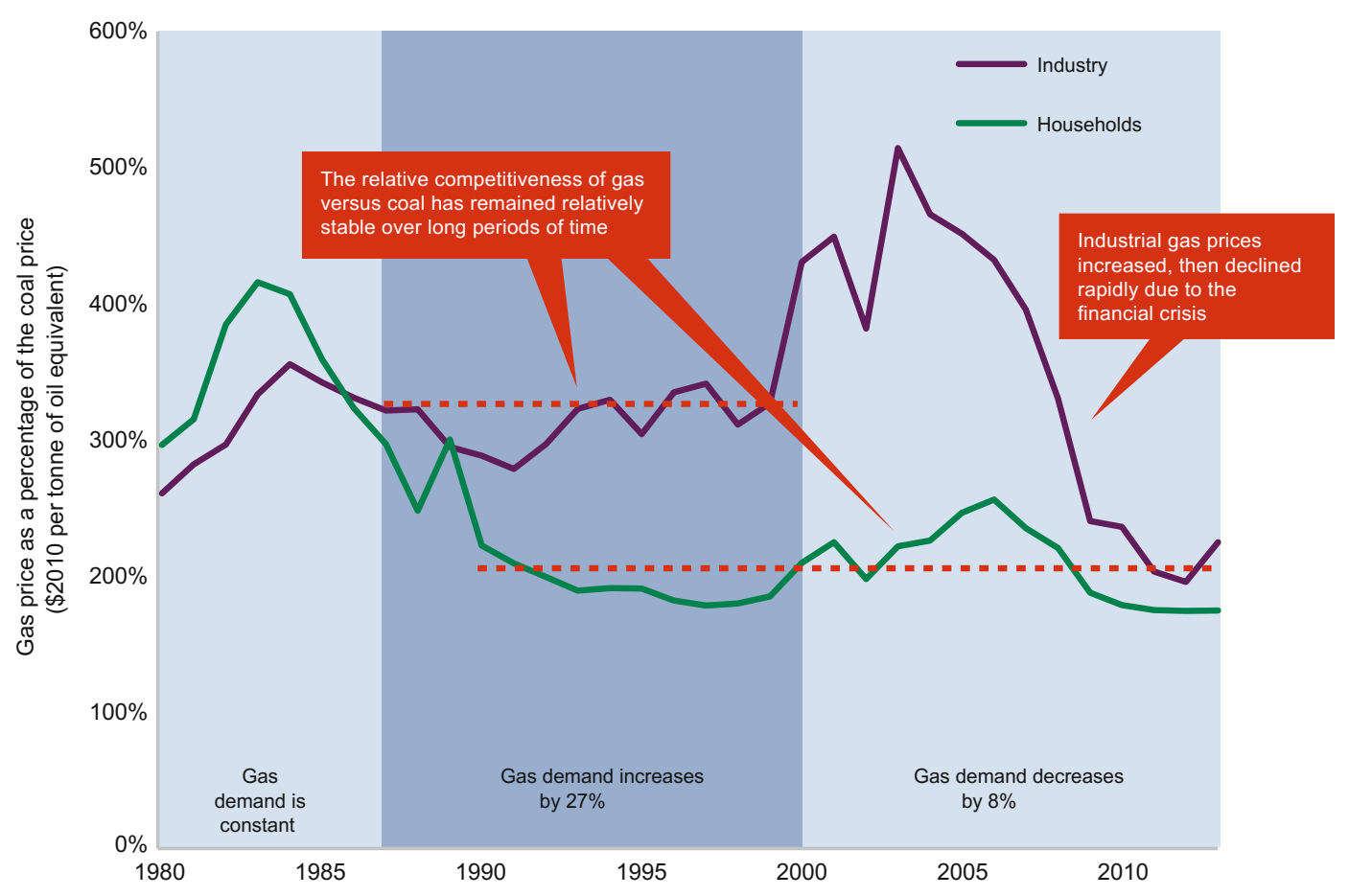

Fig. 2.25 Natural gas and coal price difference and demand growth. Note Natural gas demand is for industrial and residential usage. The red dotted line is the average level during the same period of time. Data source Vivid Economics quoting the IEA

significant role. Another conclusion that can be drawn is that pricing competition between energy sources is not actually all that pronounced.

Among OECD countries, competition between oil and natural gas is only on a small scale. In OECD countries, natural gas is generally not used as a transportation fuel, so it rarely competes with oil. In addition, oil is now less likely to be used for power generation in OECD countries. Due to this, competition between oil and natural gas is not pronounced in these countries.

In summary, natural gas demand seems to have no pronounced relationship to the price of natural gas. So, even if the price of natural gas in China remained high, it is not that likely to reduce demand for gas. Even though in OECD countries the price of gas is more competitive and gas has a higher overall share, these countries have not seen an increased demand for natural gas due to pricing competition between different energy sources. This is a direct result of the important non-pricing-related characteristics of gas. These results show that even though gas prices in China have been high in the past, other factors such as urbanisation and atmospheric pollution that are now confronting China will most likely result in major growth in demand for natural gas.

\subsection{Current State of Natural Gas Use in China and Future Trends}

\subsubsection{Sector Distribution and Total Gas Consumption in China Since 2000}

\section{China's natural gas industry has grown rapidly, but overall share is still low}

Due to its relative abundance, coal has always played a major role in China's energy mix-its share of total energy consumption has never been 
less than $65 \%$. After coal, oil is the second most important energy source, accounting for around $20 \%$ of total energy consumption. Natural gas consumption is the lowest, with a share not exceeding $6 \%$, and the low amount of clean energy in the overall mix is a major deficiency. In 2000, China's natural gas consumption was only 24.5 billion $\mathrm{m}^{3}$, with $2.2 \%$ of total energy source consumption. This had risen to 106.9 billion $\mathrm{m}^{3}$ by 2010 , having tripled in size. However, the total energy source share only reached $4.4 \%$. In 2013, China's natural gas consumption had reached 166.0 billion $\mathrm{m}^{3}$, accounting for $5.8 \%$ of total energy consumption (Fig. 2.26).

By looking at production and consumption, we can arrive at the following conclusions: first, an energy source structure focused on coal and oil will be hard-pressed to achieve fundamental change over a long period of time. Second, the importance of natural gas in China's energy source system is continually rising, but it is far from occupying a central position. To increase natural gas production and consumption would still require major government policy support.

\section{Natural gas is primarily used in manufac- turing, power generation and residential}

In terms of sector distribution in China, the manufacturing industry has always been the main user of natural gas. In 2000, the manufacturing industry consumed 11.8 billion $\mathrm{m}^{3}$ of natural gas, accounting for $48.5 \%$ of China's total natural gas consumption. In 2003, this figure reached $50 \%$, the highest ever. Subsequently, the share began to decrease, and 2010 consumption was 57.3 billion $\mathrm{m}^{3}$ (33.4\% of total natural gas consumption).

Power generation is the sector with the fastest growth in natural gas consumption. In 2000, the power industry consumed 800 million cubic metres of natural gas, only $3.3 \%$ of total natural gas consumption. By 2006, this had doubled to $7.0 \%$, and in 2012 it reached 23.5 billion $\mathrm{m}^{3}$, $16.0 \%$ of China's total natural gas consumption.

Transport and residential are two other major sectors using gas. In 2000, transport and shipping used 880 million $\mathrm{m}^{3}$, accounting for $3.6 \%$ of total consumption. By 2012, this had risen to 15.5 billion $\mathrm{m}^{3}$, or $10.6 \%$ of consumption.

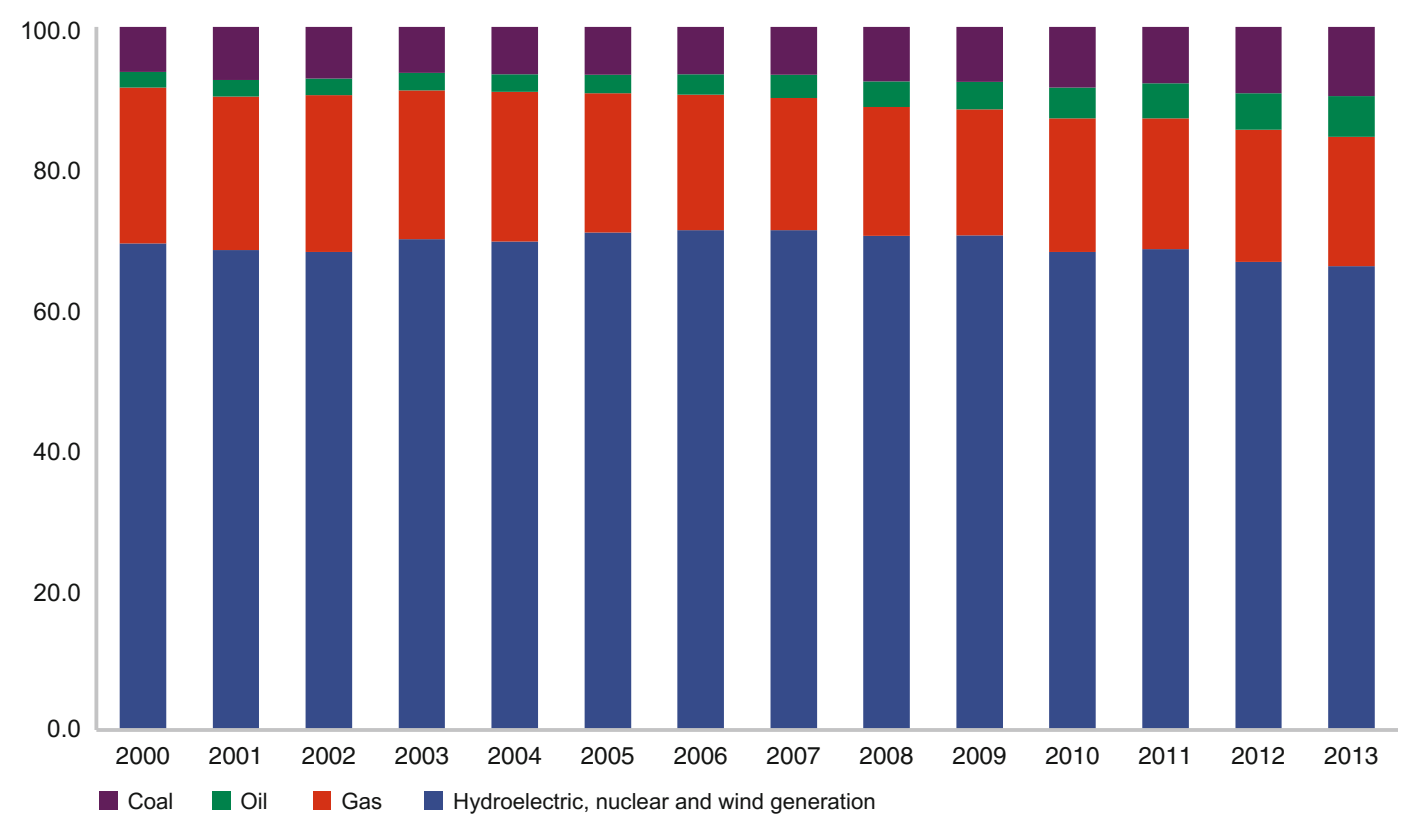

Fig. 2.26 Chinese energy source consumption structure (\%) 


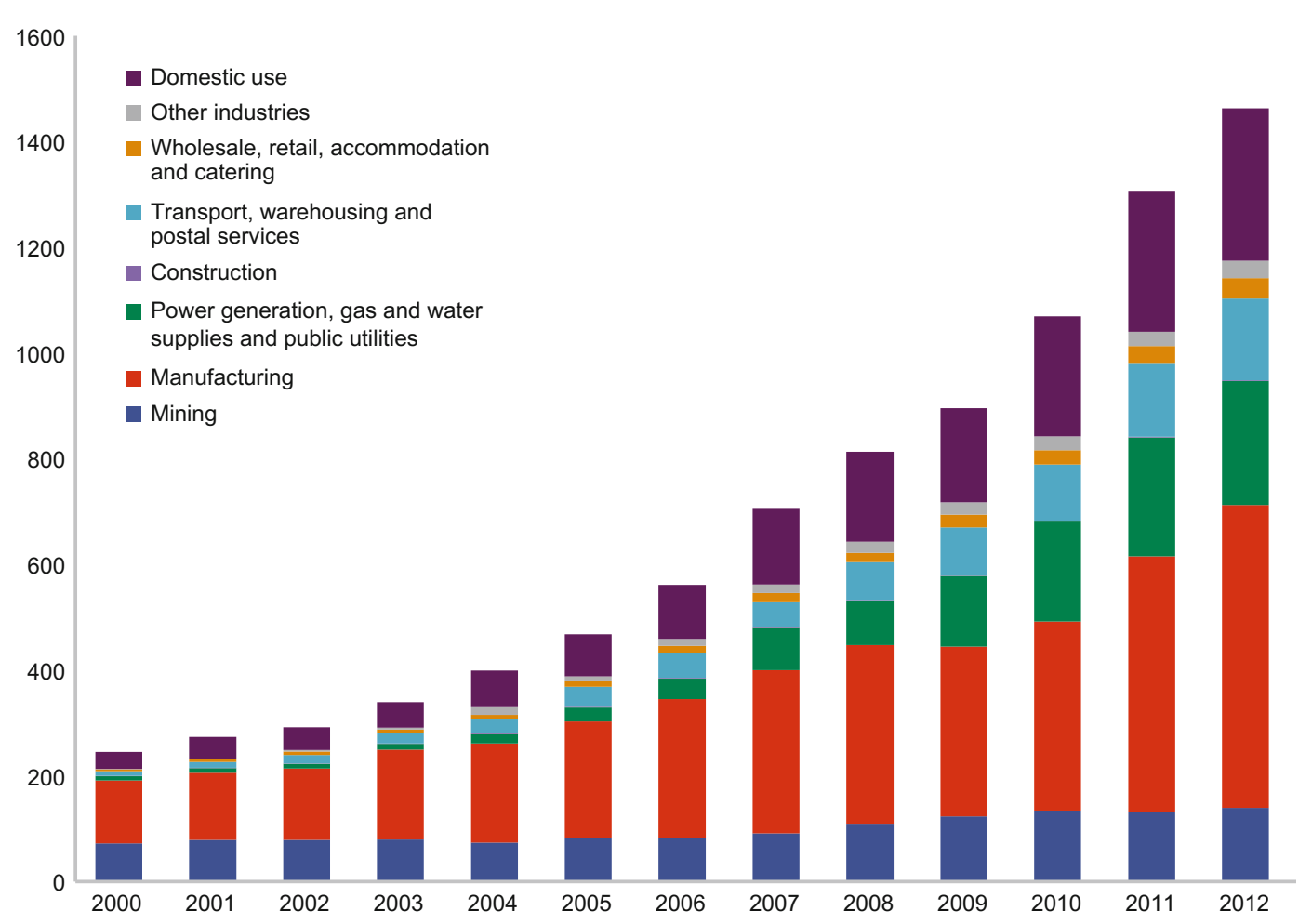

Fig. 2.27 Natural gas consumption in China by sector

Relatively speaking, the residential natural gas consumption share has been relatively stable. In 2000, residential consumption accounted for $13.2 \%$ of overall consumption, and this had risen to $19.7 \%$ by 2012 (Fig. 2.27).

\section{Compared to other countries, China's natural gas prices are relatively high}

In recent years, China's natural gas prices have increased relatively quickly. In the late 1980s, China's natural gas price was relatively low and stable. However, since 2000 the price of China's imported natural gas has risen, just as it has in the United Kingdom and Japan, as can be seen in Fig. 2.28. There was a decline in 2008 as a result of the Global Financial Crisis, but the rise continued after 2009.

Compared to other countries, at the same time as China experienced rapid growth in demand for natural gas it also had a relatively high natural gas price. Figure 2.29 shows rapid growth in demand for natural gas in OECD countries in the 1990s, but at that time prices were relatively low. China now experiences relatively high prices, a pronounced characteristic of the development of natural gas. In addition, China's natural gas market also exhibits problems, including price differences between users: compared with the situation elsewhere in the world, in China natural gas production prices are lower, residential natural gas prices are lower, but natural gas prices for industrial use are higher.

\subsubsection{Mid- to Long-Term Energy and Natural Gas Development Plans in China}

In 2013, the State Council published the Energy Source Development 12th Five-Year Plan. In June 2014, the State Council issued the Energy Source Development Strategy Action Plan 


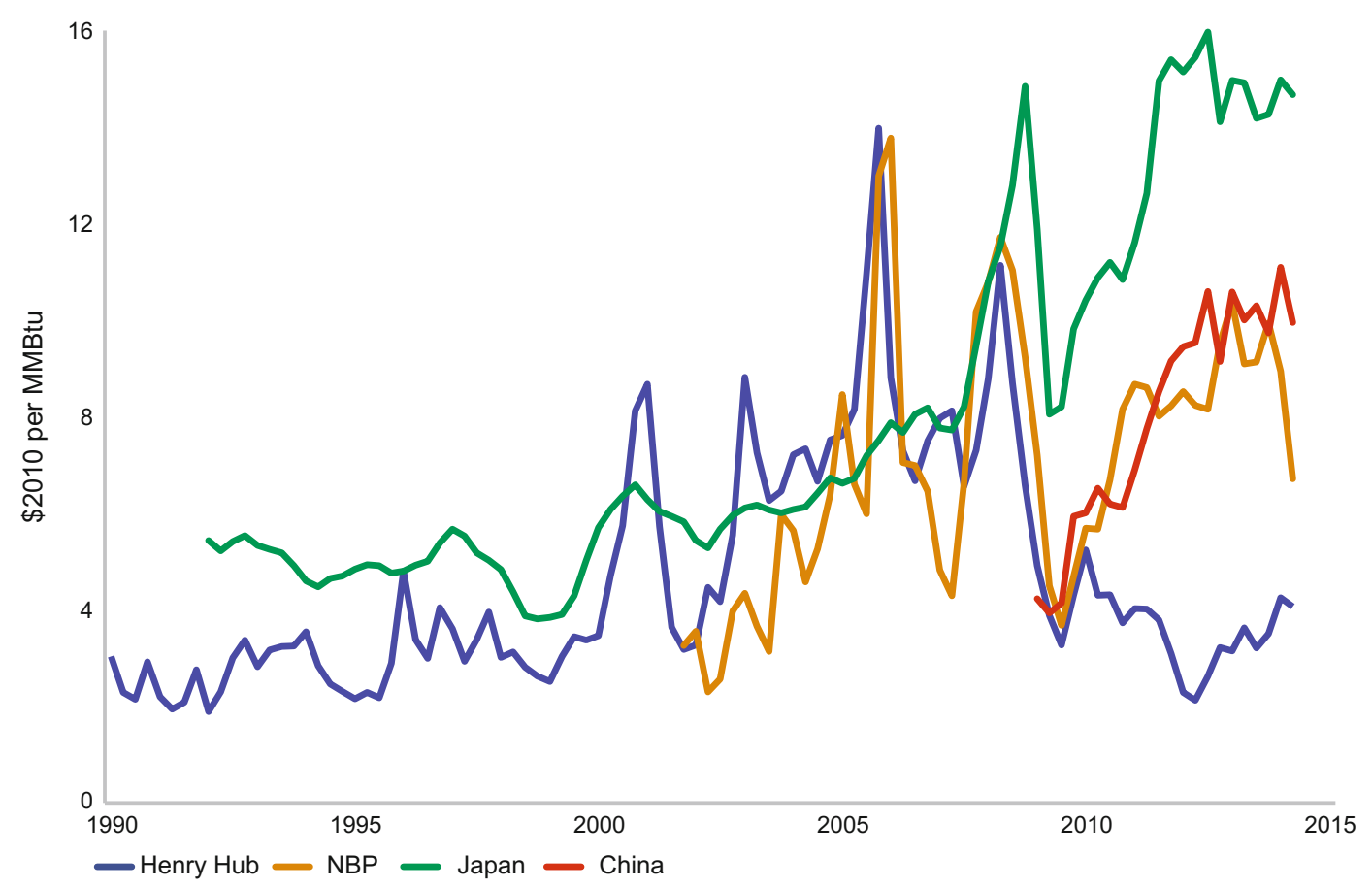

Fig. 2.28 Natural gas prices in China and other countries. Data source Vivid Economics

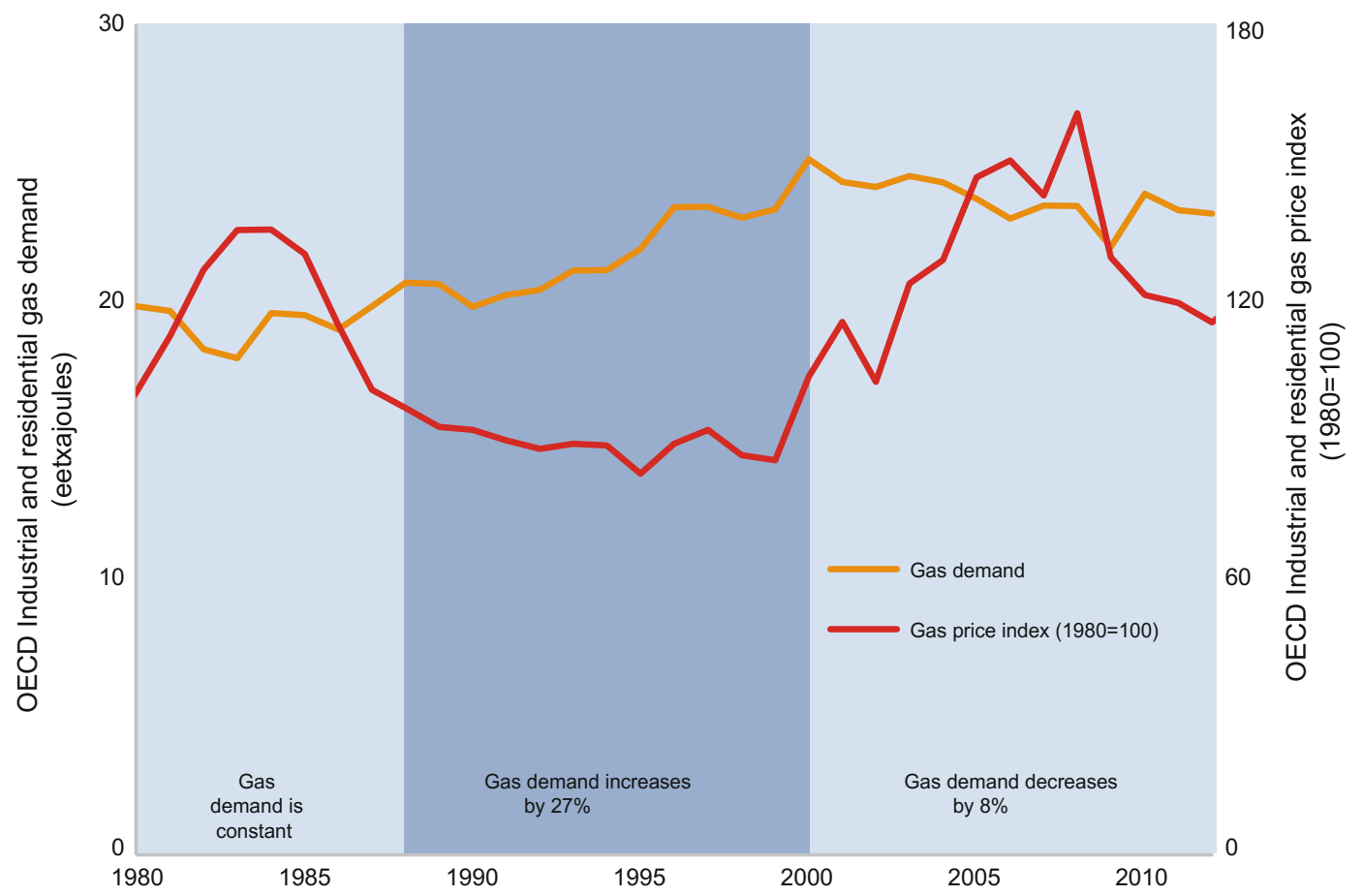

Fig. 2.29 Long-term movements in natural gas price and demand in OECD countries 
(2014-2020) and in November 2014 China and the United States published the Sino-American Joint Declaration on Climate Change. These important documents laid out planning and outlines for China's energy source development up to 2030. Based on these documents, China's energy source development plan includes several important landmark tasks.

\section{Overall energy consumption and energy supply capabilities}

Prior to updating its energy statistical data, China set objectives for total volume of energy development.

In 2015, China's energy consumption will reach 4 billion tons of standard coal. By 2020, non-renewable energy consumption will be controlled at around 4.8 billion tons of standard coal, with total standard coal consumption controlled at around 3.0 billion tons, a drop of $62.5 \%$ in the proportion of total energy consumption.

By 2020, a relatively comprehensive energy security system will have been established. Domestic non-renewable energy source output will have reached 4.2 billion tons of standard coal, with energy self-sufficiency maintained at around $85 \%$. In addition, the oil production to storage ratio will have increased to $14-15$. By 2020 , installed generating capacity of nuclear energy will have reached $58 \mathrm{GW}$, with another $30 \mathrm{GW}$ of capacity under construction.

\section{Energy source structure}

By 2015, non-fossil fuel's share of energy source consumption will have risen to $11.4 \%$, and non-fossil fuel's share of installed power generation capacity will have reached $30 \%$. The natural gas primary energy source consumption share will have risen to $7.5 \%$, while coal's share of consumption will have dropped to around $65 \%$. By 2020, non-fossil fuel energy sources will account for $15 \%$ of primary energy consumption, natural gas's share will have reached $10 \%$ and coal's share will be controlled to within $62 \%$. Newly added natural gas will be earmarked to support residential usage and replace dispersed coal usage, while a programme will be introduced to encourage urban residents to adopt clean energy sources. By 2020, urban residents will essentially be using natural gas. By 2020, an attempt will have been made to ensure that standard hydroelectric power reaches around 350 million $\mathrm{kW}$ of installed capacity, while wind power will reach 200 million $\mathrm{kW}$ of installed capacity. The feed-in price of wind-generated and coal-generated electricity should be the same. Photovoltaic installed capacity will reach around 100 million $\mathrm{kW}$. The price of photovoltaic electricity should be the same as the power grid electricity sale price.

By 2020, accumulated newly added proven reserves of conventional gas will be 0.55 trillion $\mathrm{m}^{3}$, with annual production of standard natural gas of 185 billion $\mathrm{m}^{3}$. By 2020, shale natural gas production will aim to exceed 30 billion $\mathrm{m}^{3}$, while coalbed methane production volumes will aim to reach 30 billion $\mathrm{m}^{3}$.

\section{Long-term objectives of the Chinese government to be achieved by 2030}

In November 2014, during the APEC summit, China and the United States released their Sino-American Joint Declaration on Climate Change, which revealed the long-term objectives of China up to 2030. China's intentions are that $\mathrm{CO}_{2}$ emissions should peak by around 2030 and work should be carried out to try to achieve this peak sooner. Planning outlines include 2030 non-fossil fuel energy sources rising to account for around $20 \%$ of primary energy source consumption.

\subsubsection{Mid- to Long-Term Natural Gas Development Trends for China Based on International Experiences}

Compared to other countries, the share of China's current energy source consumption accounted for by natural gas is at a relatively low 
level. This is partly due to the available natural resources, but as the economy and society develop, the effects of conflicts in supply and demand and of environmental restrictions on resources in relation to energy consumption will alter. As a result, the overall structure of China's natural gas consumption will differ from that seen in the past.

Based on the experiences of seven countries with similar natural environments and availability of natural gas resources, natural gas development is primarily influenced by growth in the service sector as a share of economic activity, degree of urbanisation and the urgency of controlling atmospheric pollution. Europe, the United States and Australia have all made significant adjustments to allow for the transition from coal to natural gas.

China has a potentially enormous demand for natural gas. With suitable policies, the natural gas share of energy consumption will rise considerably. As China's current economic development enters a "new normal", especially with the service sector share already exceeding that of secondary industry, and as further urbanisation continues to take place, and in recent years much greater attention has been paid to air quality, it can be predicted that China's natural gas consumption will see increasingly rapid growth.

In 2000, China's natural gas consumption was only 24.5 billion $\mathrm{m}^{3}$, accounting for $2.2 \%$ of total energy consumption. In 2014, China's natural gas consumption was 183 billion $\mathrm{m}^{3}, 5.8 \%$ of total energy consumption. Looking at the breakdown of consumption, the manufacturing industry is showing a declining trend, dropping from a high of $50 \%$ of total natural gas consumption down to $33.4 \%$ currently. Power generation has risen from its 2000 share of $3.3 \%$ up to the current $16.0 \%$. Transport and residential usage of natural gas have grown relatively rapidly, with shares rising from 3.6 and $13.2 \%$ in 2000 to 10.6 and $19.7 \%$ respectively in 2012 . Looking at the long term, demand for natural gas in China will continue to show a trend for rapid growth.
Open Access This chapter is licensed under the terms of the Creative Commons Attribution 4.0 International License (http://creativecommons.org/licenses/by/4.0/), which permits use, sharing, adaptation, distribution and reproduction in any medium or format, as long as you give appropriate credit to the original author(s) and the source, provide a link to the Creative Commons license and indicate if changes were made.
The images or other third party material in this chapter are included in the chapter's Creative Commons license, unless indicated otherwise in a credit line to the material. If material is not included in the chapter's Creative Commons license and your intended use is not permitted by statutory regulation or exceeds the permitted use, you will need to obtain permission directly from the copyright holder. 